\title{
Impact of ship operations aided by voyage optimization on a ship's fatigue assessment
}

\author{
Xiao Lang $^{1} \oplus \cdot$ Helong Wang ${ }^{1} \cdot$ Wengang Mao ${ }^{1} \cdot$ Naoki Osawa $^{2}$
}

Received: 1 April 2020 / Accepted: 9 September 2020 / Published online: 24 September 2020

(c) The Author(s) 2020

\begin{abstract}
In this study, different operation factors affecting a ship's wave statistics are studied, such as the slow steaming and voyage optimizations. Especially, the impact of various voyage optimization methods on the long-term wave statistics and corresponding fatigue damage during ship operations is investigated by comparing the encountered waves with the design wave scatter diagram. Three years of full-scale measurements from a container ship sailing in the North Atlantic are employed to study the impact, in addition to noon reports from two fleets of container ships and VLCCs. Furthermore, the benefits of using voyage optimizations for minimum fatigue damage accumulation during operation are discussed. The large difference of wave statistics is found when the ship follows routes generated by various optimization methods and the design diagram. For some westbound voyages, the voyage optimization methods can significantly decrease the ship's fatigue damage accumulations, leading to longer fatigue life.
\end{abstract}

Keywords Wave statistics $\cdot$ Fatigue damage $\cdot$ Full-scale measurements $\cdot$ Ship operation $\cdot$ Voyage optimizations

\section{Introduction}

Cyclic wave loads applied to ships can cause fatigue problems in ship structures. Especially for large ships with more flexible hulls, the fatigue life of 25 years should be considered in the design stage using conventional highcycle fatigue assessment principles, i.e., the $S-N$ approach [1]. However, significant uncertainties still widely exist in today's fatigue design methods [2], such as the fatigue assessment methods [3], wave load and structural stress calculations [4], input wave statistics [5, 6], etc. Figure 1 presents a typical procedure for direct fatigue assessment according to classification guidelines [1], and possible uncertainties associated with each step of the fatigue assessment.

These uncertainties in a ship's fatigue design methods have contributed to large fatigue failures (cracks) in today's

Xiao Lang

xiao.lang@chalmers.se

1 Department of Mechanics and Maritime Sciences, Division of Marine Technology, Chalmers University of Technology, 41296 Gothenburg, Sweden

2 Department of Naval Architecture and Ocean Engineering, Osaka University, Osaka, Japan ship structures [7, 8]. The investigation by Jordan and Cochran [9], as well as Jordan and Knight [10] of the commercial ships in the United States, showed that there were, on average, 86 structural failures (cracks) per ship at any inspection. In the marine technology research community, uncertainties related to fatigue methods, wave load, and structural stress analysis have been extensively investigated during the last decades [11-16]. However, the uncertainties associated with the difference between design wave scatter diagram and a ship's actual encountered wave statistics are seldom discussed, even though such difference has been reported by ISSC [2], Olsen et al. [5], Mao [17], Mao et al. [18], Bitner-Gregersen et al. [19], De Gracia et al. [20], etc.

For example, under the help of modern navigation tools in a ship's operations, such as weather routing, voyage optimization, and performance monitoring systems [21], ships are operated in more calm sea environments in comparison with the scatter diagram used for today's ship fatigue design. Besides, the global climate change may lead to high waves in a ship's future sailing scenarios [22]. The wave statistics are provided by the classification guidelines that reflect the long-term distribution of waves encountered by all ships sailing at specific areas [23]. The actual wave environment encountered by individual ships may not be consistent with that provided by the classification society guidelines 


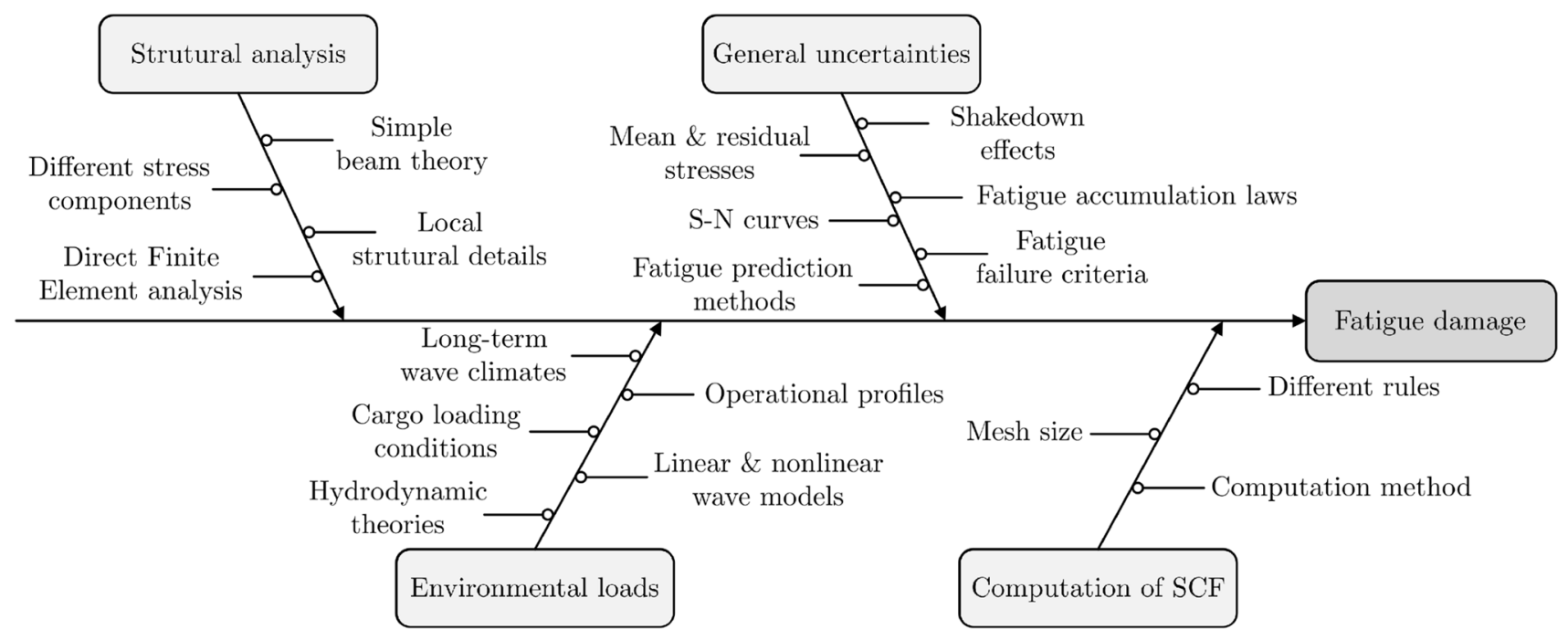

Fig. 1 Modeling diagrams of ship response (stress) and associated uncertainties for fatigue analysis

[24]. To provide more realistic wave information for ship design and operation, various sensors have been launched to collect wave data, e.g., buoy data, onboard observations, satellite measurements, and reanalysis data [25, 26]. In addition, various statistical wave models have been developed to model and simulate wave environments along a ship's actual sailing routes. Then, that generated wave information can be taken as input for ship fatigue design and extreme loading predictions [27-29], etc.

This study investigates the influence of various voyage planning methods on the wave statistics and corresponding damage accumulation compared with their design conditions. The considered voyage planning methods include adjusting a ship's speed and heading along her conventional routes to avoid harsh sea environments by either experience and/or various optimization systems. Noon reports from a fleet of container ships and VLCCs, as well as their encountered wave environments extracted from hindcast database, are used for the analysis. Especially, the 3-year "long-term" measurement data from a 2800TEU container ship are used to study how various voyage optimization methods can affect the encountered wave environments in comparison with the guidelines and actually encountered. Finally, the potential benefit of using voyage planning to reduce fatigue damage is investigated for the 2800TEU container ship.

For the completeness of the paper, the conventional direct fatigue estimation method is briefly introduced in Sect. 2 to show the importance of input wave statistics on a ship's fatigue life. In addition, some evidences of how the current navigation changes will affect a ship's encountered wave statistics are also shown. In Sect. 3, various voyage planning methods are presented to demonstrate their influence and theoretical connections with a ship's fatigue damage accumulations. Section 4 presents the details of a case study ship with full-scale measurements of encountered wave statistics and time series of stress measurements. The differences in measured wave statistics and fatigue damage are compared with that from classification guidelines. Results of various voyage operation methods on the wave statistics and fatigue accumulation are compared and discussed with the observed values. The conclusion and some key references are given at the end of the paper.

\section{Spectral fatigue method and wave statistics}

Ship fatigue design is normally based on stress-based approaches, i.e., high-cycle fatigue principles. In the analysis, the number of cycles to failure $N$ under a stress cycle range $S$ is often described by the so-called $S$ - $N$ curve:

$\log (N)=\log (\alpha)-m \log (S)$,

where the parameters $\alpha$ and $m$ depend on structural materials, geometries, working environments, and method of fabrication (welding details), etc. In this study, the Ib $S-N$ curve with $\alpha=10^{12.76}$ and $m=3$ (DNV GL [1]) is assumed in the following analysis. The fatigue accumulation under a time series of stresses is normally calculated by the linear Palmgren-Miner law as:

$D(n)=\sum_{i=1}^{n} \frac{S_{i}^{m}}{\alpha}$

where $S_{i}(i=1, \ldots, n)$ are stress ranges obtained by the rainflow counting method from the stress series [30]. 


\subsection{Direct fatigue estimation by the spectral method}

In addition to the rainflow counting method, Fig. 2 presents a schematic workflow for a direct calculation fatigue along a ship voyage under certain loading conditions. One voyage is composed of a series of stationary sea states denoted by the waypoint location $\overrightarrow{\boldsymbol{P}}$ and corresponding operational conditions $\boldsymbol{U}(\overrightarrow{\boldsymbol{P}})$. The encountered sea states are denoted by $\boldsymbol{W}(\overrightarrow{\boldsymbol{P}})=\left[\boldsymbol{W}_{1}, \boldsymbol{W}_{2}, \ldots, \boldsymbol{W}_{n}\right]$, where one sea state $\boldsymbol{W}$ is described by a wave spectrum $S_{\mathrm{w}}(\omega)$, e.g., Pierson-Moskowitz or JONSWAP, in terms of significant wave height $H_{\mathrm{s}}$ and wave period $T_{z}$.

Let a ship be sailing with a specific ship speed and heading angles $\boldsymbol{U}=\left[V, \theta_{\mathrm{S}}\right]^{T}$ under a stationary sea state $\boldsymbol{W}=\left[H_{\mathrm{s}}, T_{z}, \theta_{\text {wave }}\right]$, the structural stress for fatigue assessment is often assumed to be Gaussian and uniquely defined by its mean value and spectrum. Often, a stress concentration factor is added in the transfer function to get the local stresses. The corresponding stress response spectrum under such a sea state can be computed by:

$S_{x}\left(\omega \mid V, \theta, H_{\mathrm{s}}, T_{z}\right)=\left|H_{\sigma}(\omega \mid V, \theta)\right|^{2} S_{\mathrm{e}}\left(\omega \mid H_{\mathrm{s}}, T_{z}\right) \mathrm{d} \omega$,

where $H_{\sigma}(\omega \mid V, \theta)$ is the transfer function or response amplitude operators (RAOs) of local structural stresses. In this study, to get $H_{\sigma}$, various wave bending moments are first estimated by hydrodynamic analysis based on a 2D potential theory. Then, hull girder stresses caused by those bending moments are estimated by the beam theory. The stress concentration factor 2 is assumed to calculate the local stresses from the girder stresses [6]. In Eq. 3, $S_{\mathrm{e}}\left(\omega \mid H_{\mathrm{s}}, T_{z}\right)$ is the encountered wave spectrum that may not always be expressed explicitly for all wave frequencies. Instead, it is enough to only obtain the spectral moments of the structural stress response for a ship's fatigue assessment. The $n$th order spectral moments $\lambda_{n}$ can be calculated by: $\lambda_{n}=\int_{0}^{\infty}\left|\omega+\frac{\omega^{2} V \cos \theta}{g}\right|^{n} H_{\sigma}^{2}(\omega \mid V, \theta) S_{\mathrm{e}}\left(\omega \mid H_{\mathrm{s}}, T_{z}\right) \mathrm{d} \omega$.

Let $R$ denote the local maximum of the Gaussian stress response in such a sea state $\boldsymbol{W}$. The distribution of $R$ follows Rice's distribution. If the stress is assumed to be narrowband Gaussian processes with zero spectral width parameter, then $R$ follows a Rayleigh distribution:

$F_{R}(r)=1-e^{-\frac{r^{2}}{2 \lambda_{0}}}, \quad(r \geq 0)$,

where $\lambda_{0}$ is zero-order spectral moment. In a stationary sea state, the stress range $S$ is a random variable with a probability density function denoted by $f_{S}(s)$. Then, the expected value of $S^{m}$ is computed by $E\left[S^{m}\right]=\int_{0}^{\infty} s^{m} f_{S}(s) \mathrm{d} s$. For a zero mean narrow-band Gaussian process, the stress cycle range $S$ is approximated by two times of the stress amplitude $R$, i.e., $S \approx 2 R$. Subsequently, by means of Eq. $5, E\left[S^{m}\right]$ can be computed by:

$E\left[S^{m}\right] \approx \int_{0}^{\infty}(2 r)^{m} f_{R}(r) \mathrm{d} r=\left(2 \sqrt{2 \lambda_{0}}\right)^{m} \Gamma\left(\frac{m}{2}+1\right)$,

where $\Gamma(x)$ is the gamma function. Finally, the expected fatigue damage is computed by:

$E[D]=\frac{N_{0}}{\alpha} E\left[S^{m}\right] \approx \frac{T}{2 \pi \alpha} \sqrt{\frac{\lambda_{2}}{\lambda_{0}}}\left(2 \sqrt{2 \lambda_{0}}\right)^{m} \Gamma\left(\frac{m}{2}+1\right)$,

where $N_{0}$ is the expected number of stress cycles $N_{0}=\frac{T}{2 \pi \alpha} \sqrt{\frac{\lambda_{2}}{\lambda_{0}}}$, and $T$ is the duration of a stationary sea state lasting for a period from $30 \mathrm{~min}$ to several hours. The spectral method in Eq. 7 is also known as the narrow-band approximation of the rainflow damage for the stationary sea state. If the time series of stress measurement in a stationary sea state is available, the spectral moments in Eq. 7 can be directly computed from the stress signals.

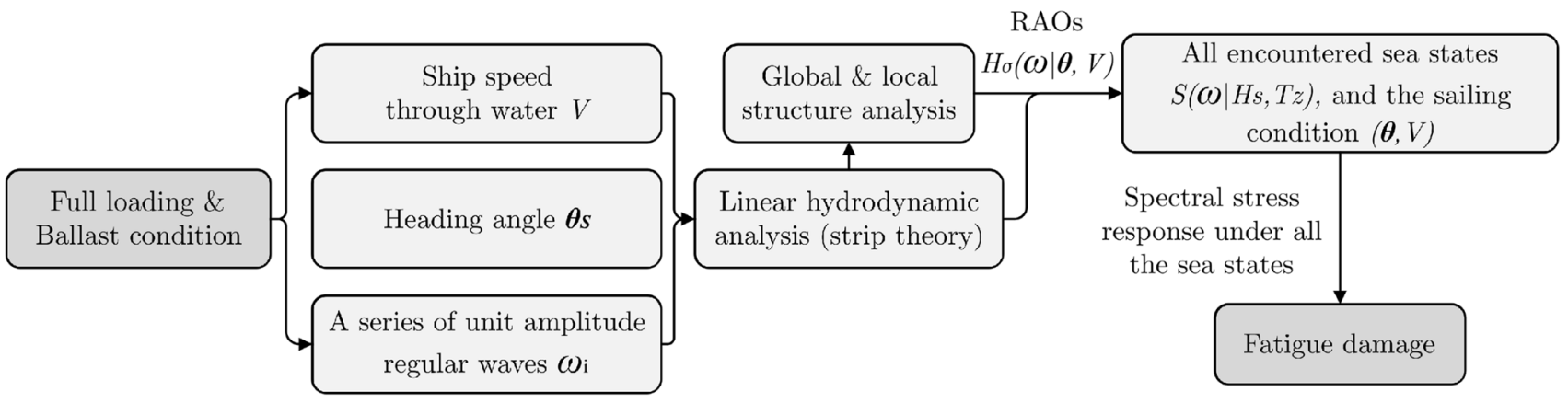

Fig. 2 Workflow of a conventional ship fatigue life prediction method with fatigue loads for direct calculations 


\subsection{Effect of slow steaming on the long-term wave statistics}

In maritime transportation, shipmaster mariners are using different operational strategies to navigate their ships, such as sprint and loiter sailing, voyage optimizations, constant speed, fixed engine power sailing, etc. [31]. Furthermore, since a ship's resistance is normally proportional to her sailing speed to the power of 2-3, lowering a ship's sailing speed can significantly reduce her resistance, leading to a large amount of fuel saving. Therefore, slow steaming, where a ship is navigated with significantly less engine power than her design engine power and sailing speed, is widely adopted operation strategy by most of today's shipping companies to minimize a ship's fuel consumption when sailing at sea.

For example, the actual engine loads of a fleet of VLCCs from their worldwide operation are extracted from their noon reports and presented in Fig. 3a. More than $70 \%$ of the ship fleet's service period, their ships are operated with marine engine loads between 40 and $65 \%$ of the MCR (maximum continuous rating) of their installed engine powers. During the slow steaming operations, ship's sailing speeds are also reduced in comparison with her service speed, leading to lower resistance and fuel consumption. Furthermore, a fleet of container ships, which are often recognized as the shipping segment with the highest sailing speed, have been experiencing slow steaming with even lower engine loads. The engine loads from the noon reports of approximate 400 worldwide voyages recorded by a large container fleet are presented in Fig. 3b. On average, only about $30 \%$ of the fleet's MCR of engines are used for the slow steaming navigations.

The slow steaming operations may also lead to observed wave statistics different from the wave scatter diagram provided by classification guidelines. For all the voyages recorded in the noon reports $(24 \mathrm{~h}$ resolution for each recorded waypoint), the waypoints for each voyage are linearly interpolated into $3 \mathrm{~h}$ resolution of waypoints. Then, the wave conditions, i.e., significant wave height $H_{\mathrm{s}}$ and wave mean period $T_{z}$, along all those waypoints are extracted from the ECMWF ERA5 hindcast dataset [33]. For the fleet of VLCCs, the extracted information of $\left[H_{\mathrm{s}}\right.$, $T_{z}$ ] along all the voyages is used to construct a wave scatter diagram, which is compared with that from the DNV GL guidelines [32] for worldwide sailing in Fig. 4. A large difference between the actual and design wave scatter diagrams can be observed from Fig. 4. Much more sea states with $H_{\mathrm{s}}$ less than $2 \mathrm{~m}$ (more than $75 \%$ ) were encountered by the actual sailing, while encountered harsh sea environments with $H_{\mathrm{s}}$ larger than $5 \mathrm{~m}$ are significantly reduced from about $9 \%$ (design wave statistics) to less than $1 \%$. A similar difference can also be observed in the fleet of container ships, as in Fig. 5, but the difference is smaller than the VLCCs. For the container ships, a large difference is found for the distribution of $T_{z}$ under the same $H_{\mathrm{s}}$. For example, for the $H_{\mathrm{s}}$ of $1-3 \mathrm{~m}$, the wave period $T_{z}$ of sea states encountered during the actual sailing is significantly larger than that in the design wave scatter diagram. It can lead to less fatigue damage during the actual sailing because of less encountered waves (stress variations). One obvious reason leading to the difference of wave statistics in Figs. 4 and 5 is due to the difference between actual operation areas of these ships and the assumptions behind the classification guidelines. The slow steaming operations may also contribute to the difference. Especially, when the slow steaming is combined with voyage optimization to aid a ship's operations, the ship can have more freedom to adjust her sailing routes and speeds to avoid harsh sea conditions [34]. It can significantly reduce the probability of encountering large waves.

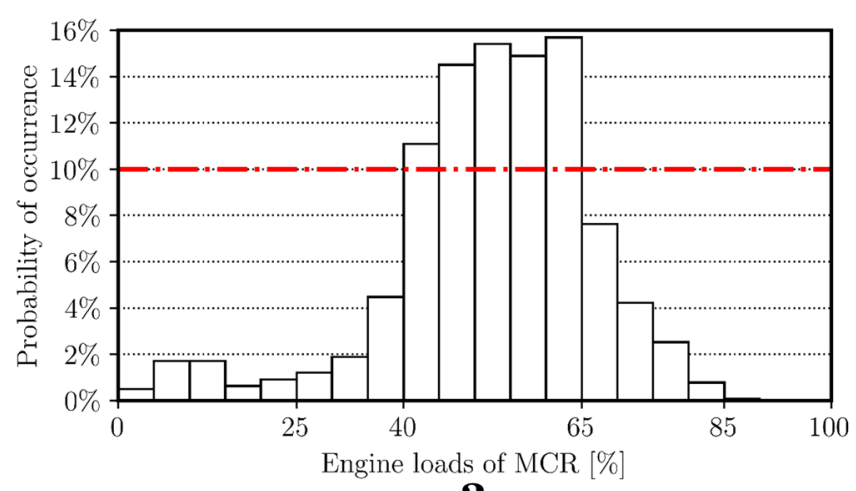

a

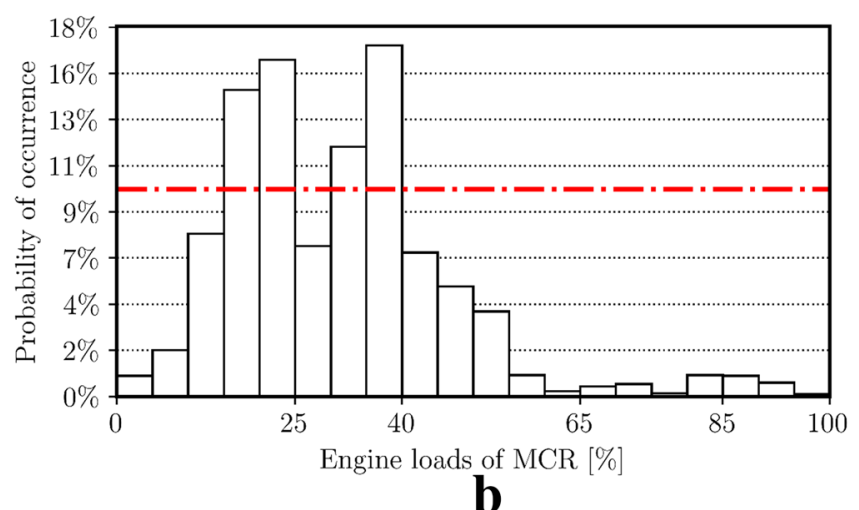

Fig. 3 The probability of different engine power for slow steaming operations recorded for two ship fleets: a VLCCs from late 2016 to 2018 (about 2.5 years), and $\mathbf{b}$ container ships from 2015 to 2016 ( 2 entire years) 


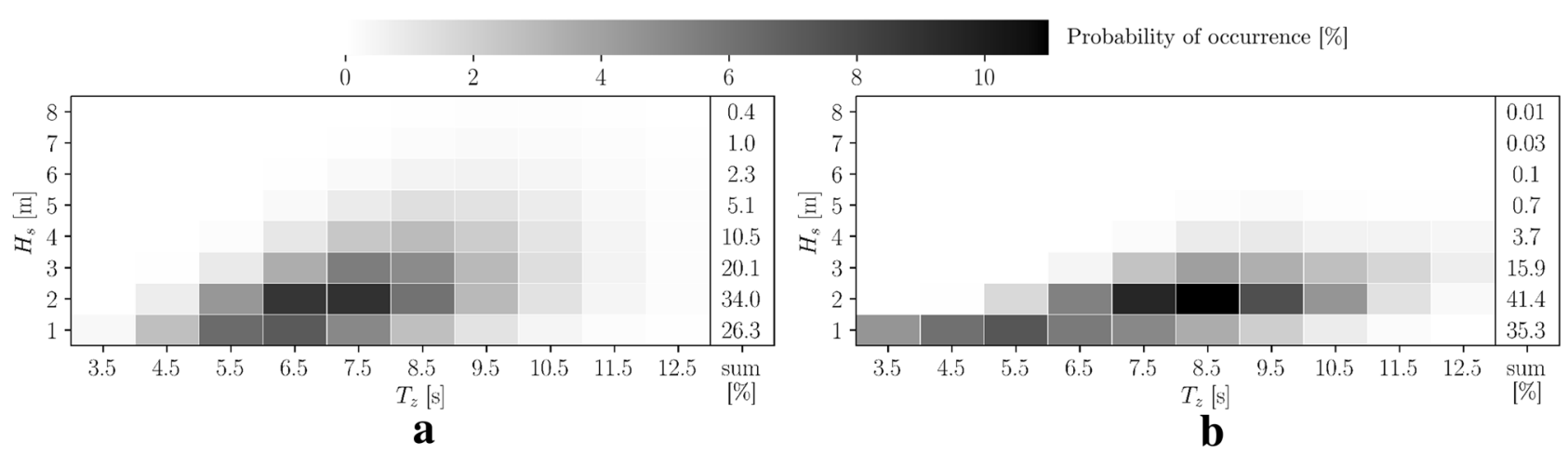

Fig. 4 Comparison of wave scatter diagrams from a DNV GL guidelines for worldwide operations [32] and b observed from a fleet of slow steaming VLCCs for worldwide service. NB: the colorbar presents the probability of occurrence

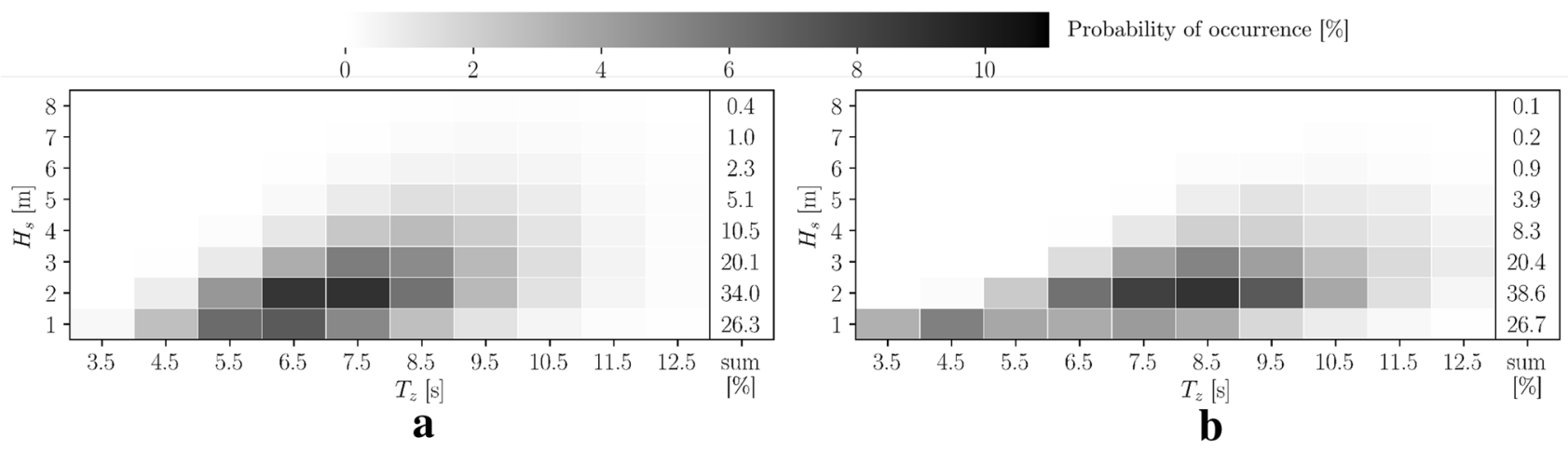

Fig. 5 Comparison of wave scatter diagrams from a DNV GL guidelines for worldwide operations [32] and $\mathbf{b}$ observed from a fleet of slow steaming container ships for worldwide service. NB: the colorbar presents the probability of occurrence

\subsection{Influences of voyage optimization on wave statistics}

Modern navigation systems used onboard today's ships, such as voyage optimization systems, weather routing systems, performance monitoring systems, etc., have led to a significant change of a ship's sailing routes and encountered sea environments. A fleet of midsize chemical tankers equipped with a well-recognized voyage optimization system is used to study navigation systems' influences on the long-term wave environments encountered by ships, especially the difference in comparison with a ship's design conditions. The full-scale measurements are recorded onboard the fleet of chemical tankers every 15 min with a ship's positions, sailing speeds, engine powers, motions, and other performance-related parameters. The measurement campaign during the year from 2013 to 2018 is used in this study. Both short-term and long-term impacts of the voyage optimization systems on a ship's encountered wave environments are investigated in this study. In addition to the wave scatter diagram, the first, second, and third moments of encountered significant wave heights $E\left[H_{\mathrm{s}}^{k}\right], k=1,2,3$ are compared to reflect the difference of wave statistics. They can be computed by:

$E\left[H_{\mathrm{s}}^{k}\right]=\int_{0}^{+\infty} h^{k} f(h) \mathrm{d} h, k=1,2,3$,

where $f(h)$ is the probability density function of the encountered $H_{\mathrm{s}}$. It should be noted that the first moment $E\left[H_{\mathrm{s}}\right]$ is the mean value of the significant wave height and the second moment $E\left[H_{\mathrm{s}}^{k}\right]$ is related to the variance of $H_{\mathrm{s}}$, while the third moment is an important measure of a ship's fatigue damage accumulation under the long-term wave environments.

First, six measured voyages when the chemical tanker fleet members were sailing in the North Atlantic during the year 2015 are selected to investigate the short-term impact of voyage optimization-aided operations on a ship's encountered wave environment. It is well known that the North Atlantic is one of the most challenging ship navigation areas. A good voyage optimization system would be greatly beneficial to ship safety, energy efficiency, and keeping time schedules, etc. In this study, three eastbound voyages and three westbound voyages are considered, as 

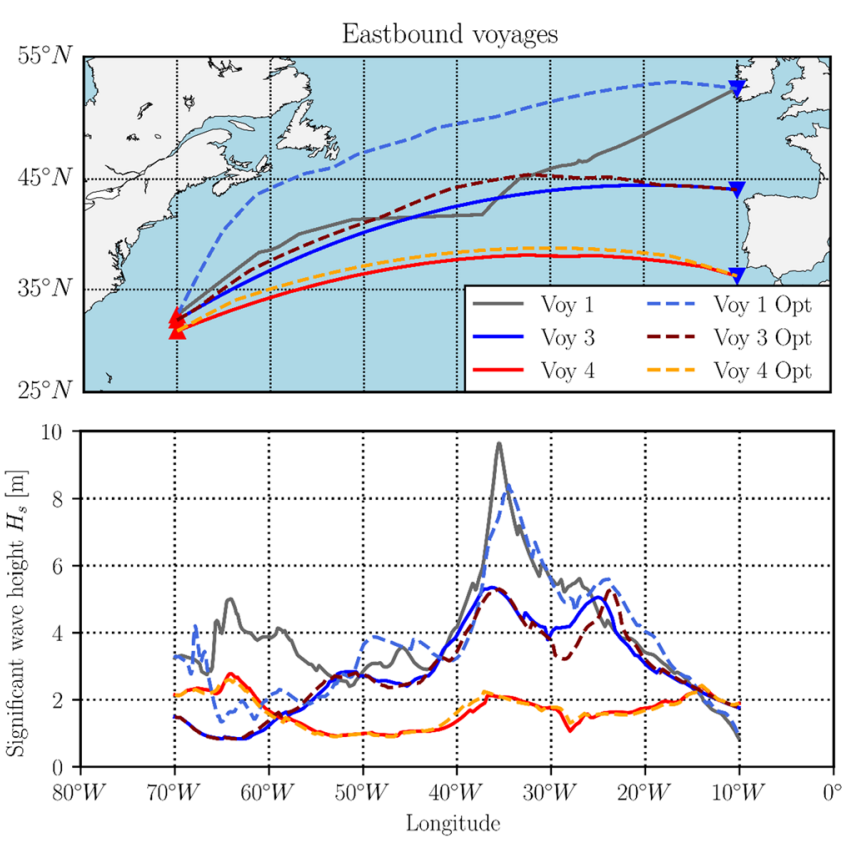

Fig. 6 Comparison of ship routes and encountered $H_{\mathrm{s}}$ by the chemical tankers between actual measurements and further optimized by a 3-dimensional Dijkstra's Algorithm proposed in [35] with the same

in Fig. 6. The red triangle-up and the blue triangle-down represent the departure and destination of the voyages, respectively. Normally, westbound winter voyages are more affected by sea environment than eastbound summer voyages, because the storms in winter are harsher, and the storms always move from the west to the east in the North Atlantic. Therefore, the westbound voyages are often treated more seriously during the voyage optimization process. This can also be seen from Fig. 6 (right plot) that the westbound routes and encountered sea environments from different voyage planning methods are more divergent from each other than the eastbound voyages.

In Fig. 6, a well-recognized weather routing system was used onboard to aid the ship operations. The solid lines represent the measured ship routes and encountered $H_{\mathrm{s}}$. These routes are further optimized by a new 3-dimensional Dijkstra's Algorithm proposed in [35], focusing on the minimum fuel consumption and the same ETA as the measured voyages. It shows in Fig. 6 (right plot) that for the westbound voyages, ship routes recommended by both voyage optimization methods differ significantly from the conventional shortest distance routes. Furthermore, for the "Voy1" (an eastbound winter voyage) in Fig. 6 (left plot), the two optimization methods also generate quite different routes and sea environments. It should be noted that in the measurements, the chemical tankers were mainly crossing the North Atlantic in summer. More differences in voyage optimizations can be expected if westbound winter voyages are investigated.
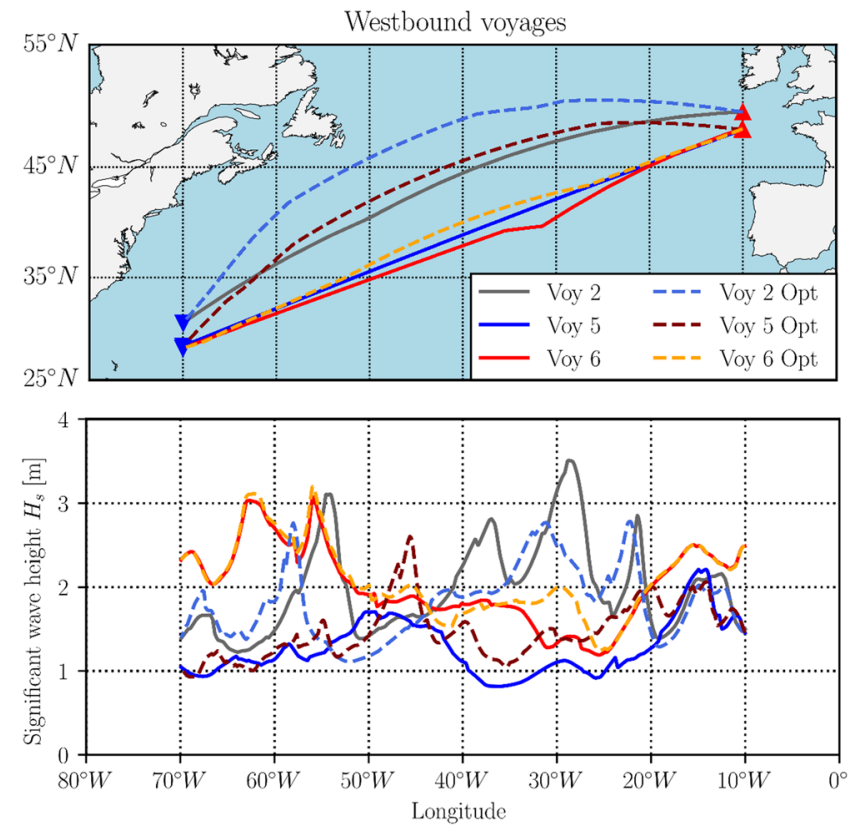

travel times as measured. The solid lines represent information from the measurements, and the dashed lines represent information from the optimized ship routes

To quantity the difference of wave statistics for those voyages due to various voyage optimization methods, the first three moments of $H_{\mathrm{s}}$ are computed and listed in Table 1. As is shown that even for these very simple voyages (most of them coming from summer seasons), there are more than $20 \%$ difference in $E\left[H_{\mathrm{s}}^{3}\right]$ that are strongly related to a ship's fatigue damage between the two optimization methods. More differences can be observed between the wave statistics from voyage optimization methods and that from the DNV GL guidelines.

For the long-term impact analysis, all 5 years of full-scale measurement data from the fleet of chemical tankers are considered. The encountered wave conditions (significant wave height $H_{\mathrm{s}}$ and mean wave period $T_{z}$ ) along the measured voyages are extracted from the same ERA5 hindcast dataset. The corresponding wave scatter diagram from the sailing

Table 1 First three moments of $H_{\mathrm{s}}$ encountered by the case study fleet of chemical tankers for their actual sailing, optimized routes, and wave scatter diagram from DNV GL guidelines for North Atlantic and worldwide sailings

\begin{tabular}{llll}
\hline Basic statistic of $H_{\mathrm{s}}$ & Actual sailing & $\begin{array}{l}\text { Optimiza- } \\
\text { tion by } \\
\text { 3DDA }\end{array}$ & $\begin{array}{l}\text { DNV GL } \\
\text { world- } \\
\text { wide }\end{array}$ \\
\hline $\begin{array}{l}\text { First moment of } H_{\mathrm{s}}, E\left[H_{\mathrm{s}}\right] \\
\text { Second moment of } H_{\mathrm{s}},\end{array}$ & 2.32 & 2.21 & 2.46 \\
$\quad \begin{array}{l}E\left[H_{\mathrm{s}}^{2}\right] \\
\text { Third moment of } H_{\mathrm{s}}, E\left[H_{\mathrm{s}}^{3}\right]\end{array}$ & 29.14 & 6.22 & 7.98 \\
\hline
\end{tabular}


voyages that were designed by a voyage optimization system is compared with the diagram from DNV GL guidelines for worldwide trade in Fig. 7.

It shows that the voyage optimization system has successfully helped the fleet to sail in the more moderate sea and avoid harsh wave conditions. Less than $2 \%$ of the fleet's service time was sailing in the sea states with $H_{\mathrm{s}}$ larger than $5 \mathrm{~m}$, compared to about $10 \%$ from the DNV GL guidelines. Additionally, waves encountered by the fleet with the onboard voyage optimization system are more concentrated at the lower significant wave height span, compared to the measurements of the aforementioned slow steaming fleets. In brief, the voyage optimization system has a great effect on the long-term wave statistics. Thus, it is more deserved to investigate the impact on the ship fatigue design.

In the following, the impact on the difference of longterm wave statistics and corresponding fatigue life between design and operation conditions is investigated by comparing various voyage optimization methods used for a ship's operations. For the ship voyage optimization methods, the input metocean conditions (wind, wave, and current, etc.) are assumed to be known, i.e., that information is extracted directly from the hindcast data sources. In addition to the variation of $\left[H_{\mathrm{s}}, T_{z}\right]$ (wave scatter diagram) caused by different optimization methods, the influences of a ship's heading angles and ship speeds during operations on the ship's fatigue accumulation are also discussed through the comparison with actual rainflow damage based on measured stress signals. For the completeness of the paper, some basic concepts of voyage optimization methods are briefly presented in Sect. 3, which is expected from theoretical perspectives to demonstrate the potential impact of voyage optimization methods on a ship's encountered wave environments. The quantitative study using the 2800 TEU container ship as a demonstration case study ship is given in the following analysis.

\section{Various voyage optimizations to guide a ship's navigation}

Ship safety and energy efficiency are the two most important factors to make shipping more competitive and sustainable [21]. These two factors are strongly related to a ship's encountered wave environment that is often considered during the voyage planning stage before departure. Currently, various computer-aided voyage optimization methods are available to help captains to plan ship routings, which can avoid potentially dangerous and harsh storm conditions with the objectives to minimize the risk of ship/cargo damage and human injures, as well as reduce fuel consumption and reach destinations at the expected time of arrival, etc. These voyage optimization methods can directly impact a ship's short-term and long-term wave statistics compared to her original design conditions. Even though the minimum fatigue damage is seldom a large concern of an optimization objective for shipping companies to plan their ship routes, voyage optimizations with respect to other objectives also have a direct impact on a ship's fatigue damage accumulation due to varying wave statistics in comparison with design conditions. In the following, voyage optimization methods with different optimization objectives are briefly presented and used for further impact analysis.

\subsection{Introduction of voyage optimization assisting ship operation}

For a computer-aided voyage optimization, the first step is to discretize the potential sailing area into a grid of waypoints, as in Fig. 8. The waypoints are defined by locations and passing times $\boldsymbol{P}_{i, j}=\left[x_{i, j}, y_{i, j}, \boldsymbol{t}_{i, j}\right]^{T}$, where the subscripts $i, j$ represent the time stage advanced along the reference route (often the great circle route) and the number of waypoints in each time stage, respectively. While

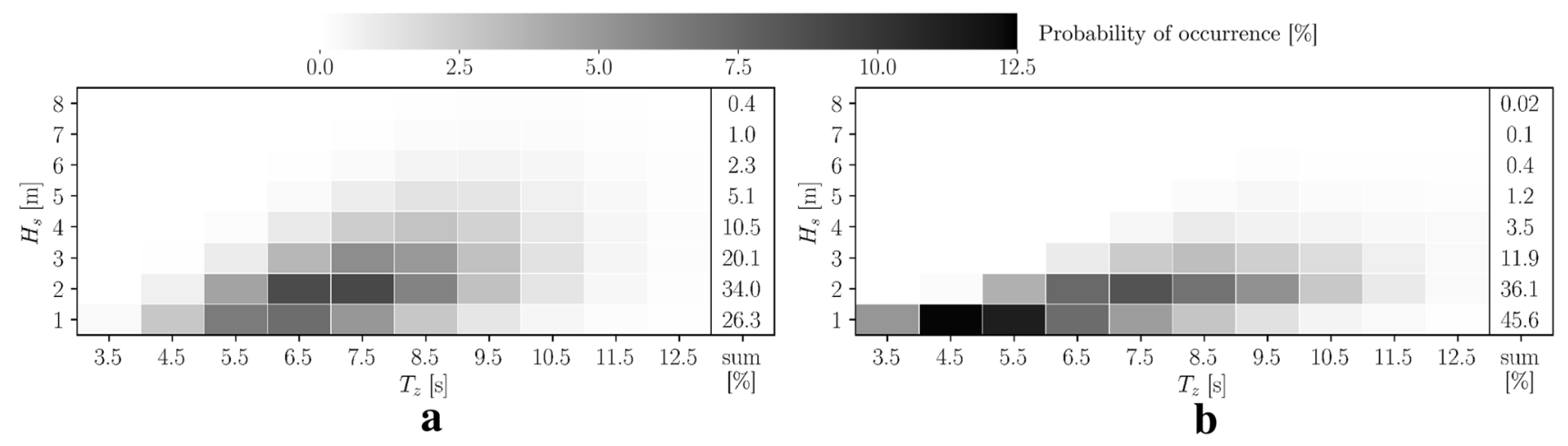

Fig. 7 Wave scatter diagram comparison between a DNV GL guidelines for worldwide operations [32] and $\mathbf{b}$ real measurements of the chemical tankers with an onboard voyage optimization system. NB: the colorbar presents the probability of occurrence 
Fig. 8 An illustration of the discretization of a potential sailing area for voyage optimization. The same discretization can be used for both eastbound and westbound voyages

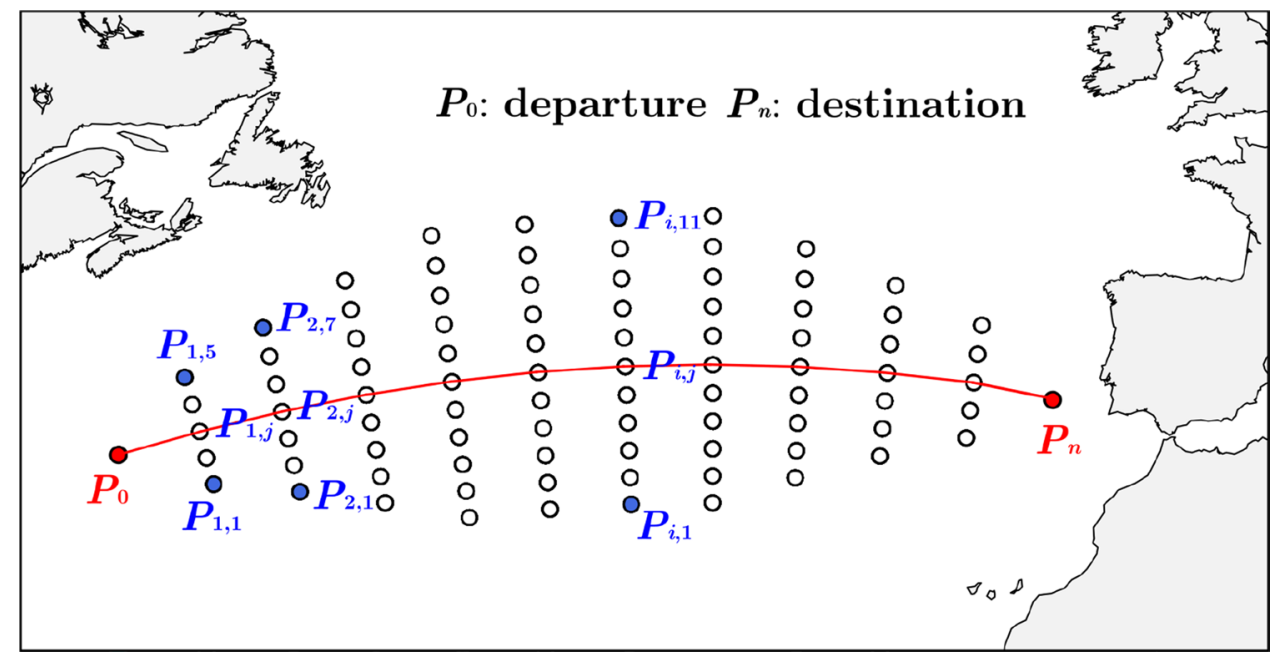

$x, y, t$ represent longitude, latitude, and possible passing times at the location $(x, y)$, respectively. At each waypoint $\boldsymbol{P}$, a ship can be navigated with various operational conditions, denoted as the operation control variables $\boldsymbol{U}(\boldsymbol{P})$, which is composed of sailing speed $V$ and ship heading $\theta_{\mathrm{S}}$. Therefore, the number of possible passing times in $t$ depends on pre-defined ship sailing speeds. Furthermore, the metocean conditions encountered at the waypoint $\boldsymbol{P}$, i.e., $\boldsymbol{W}(\boldsymbol{P})$ containing wind, wave, and current conditions, also depend on the passing time (speed). Then, for each of the waypoints in the discretized sailing area as in Fig. 8, its operational conditions $\boldsymbol{U}$ should be defined for a ship's navigation along this route based on the forecast encountered metocean environments $\boldsymbol{W}$ in this area. Let us denote the two variable vectors as:

$\boldsymbol{U}(\boldsymbol{P})=\left[V, \theta_{\mathrm{S}}\right]^{T}$ and $\boldsymbol{W}(\boldsymbol{P})=\left[H_{\mathrm{s}}, T_{z}, \theta_{\text {wave }}, V_{\mathrm{c}}, \theta_{\mathrm{c}}, V_{\mathrm{w}}, \theta_{\mathrm{w}}, \ldots\right]^{T}$,

where $H_{\mathrm{s}}, T_{z}$, and $\theta_{\text {wave }}$ represent significant wave height, mean wave period, and wave moving direction, and $V_{\mathrm{c}}, \theta_{\mathrm{c}}$, $V_{\mathrm{w}}$, and $\theta_{w}$ represent current speed, current moving direction, wind speed, and wind blowing direction, respectively. A ship's performance, such as fuel consumption, ETA, and fatigue damage accumulation, at $\boldsymbol{P}$ is determined by the choice and values of both $\boldsymbol{U}$ and $\boldsymbol{W}$.

Finally, the task of a voyage optimization method is to optimize a ship's operation control variables $\boldsymbol{U}$ for each waypoint $\boldsymbol{P}_{i, j}$, by searching for the whole discretized area based on the forecast metocean environment $\boldsymbol{W}$. A voyage optimization can find an optimal route composed of a series of waypoints $\overrightarrow{\boldsymbol{P}}=\left[\boldsymbol{P}_{0}, \boldsymbol{P}_{1, j_{1}}, \ldots, \boldsymbol{P}_{i, j_{i}}, \ldots, \boldsymbol{P}_{n}\right]$ from the discretized sailing area with to fulfil pre-defined optimization objectives, such as ETA, minimum fuel, etc. The operational conditions and corresponding metocean environments along the optimized route are described denoted by: $\begin{aligned} \boldsymbol{U}(\overrightarrow{\boldsymbol{P}}) & =\left[\boldsymbol{U}\left(\boldsymbol{P}_{0}\right), \boldsymbol{U}\left(\boldsymbol{P}_{1, j_{1}}\right), \ldots, \boldsymbol{U}\left(\boldsymbol{P}_{i, j_{i}}\right), \ldots, \boldsymbol{U}\left(\boldsymbol{P}_{n}\right)\right] \\ \boldsymbol{W}(\overrightarrow{\boldsymbol{P}}) & =\left[\boldsymbol{W}\left(\boldsymbol{P}_{0}\right), \boldsymbol{W}\left(\boldsymbol{P}_{1, j_{1}}\right), \ldots, \boldsymbol{W}\left(\boldsymbol{P}_{i, j_{i}}\right), \ldots, \boldsymbol{W}\left(\boldsymbol{P}_{n}\right)\right]\end{aligned}$

\subsection{Voyage optimization methods used in this study}

During a voyage optimization process, different inputs are required to find an optimal route $\overrightarrow{\boldsymbol{P}}$, such as the metocean data, various ship performance data, and voyage constraints. A typical voyage optimization procedure involving 6 steps is presented in Fig. 9.

During the optimization process, the objective function in the optimization algorithm is denoted by:

$J=\int_{t_{\mathrm{s}}}^{t_{\mathrm{e}}} f_{\mathrm{c}_{-} i}\left(\boldsymbol{U}\left(\boldsymbol{P}_{i}\right), \boldsymbol{W}\left(\boldsymbol{P}_{i}\right)\right) \mathrm{d} t$,

where $f_{\mathrm{c} \_i}\left(\boldsymbol{U}\left(\boldsymbol{P}_{i}\right), \boldsymbol{W}\left(\boldsymbol{P}_{i}\right)\right)$ is the instantaneous cost function for a ship waypoint $\boldsymbol{P}_{i}$ with a control variable $\boldsymbol{U}\left(\boldsymbol{P}_{i}\right)$ under the metocean environment $\boldsymbol{W}\left(\boldsymbol{P}_{i}\right), t_{\mathrm{s}}, t_{\mathrm{e}}$ are the departure and arrival times, respectively. Here, the cost function changes according to the specific optimization objectives, e.g., minimum fuel consumption, maximum allowed ship motions, expected time of arrival (ETA), and lowest fatigue damage accumulation in a ship's structure [36]. In this study, two types of cost functions are required for the voyage optimization, i.e., the cost function to estimate a ship's fuel consumption $f_{\text {c_fuel }}$, and the cost function to estimate a ship's fatigue damage accumulation $f_{\text {c_damage. }}$. The two cost functions are briefly presented in Sect. 3.3. The cost functions should be evaluated to all the waypoints in the discretized searching area as in Fig. 8. The integration of all the costs along potential ship routes as in Eq. 11 will lead to different values of $J$. The task of a voyage optimization method is to find a 


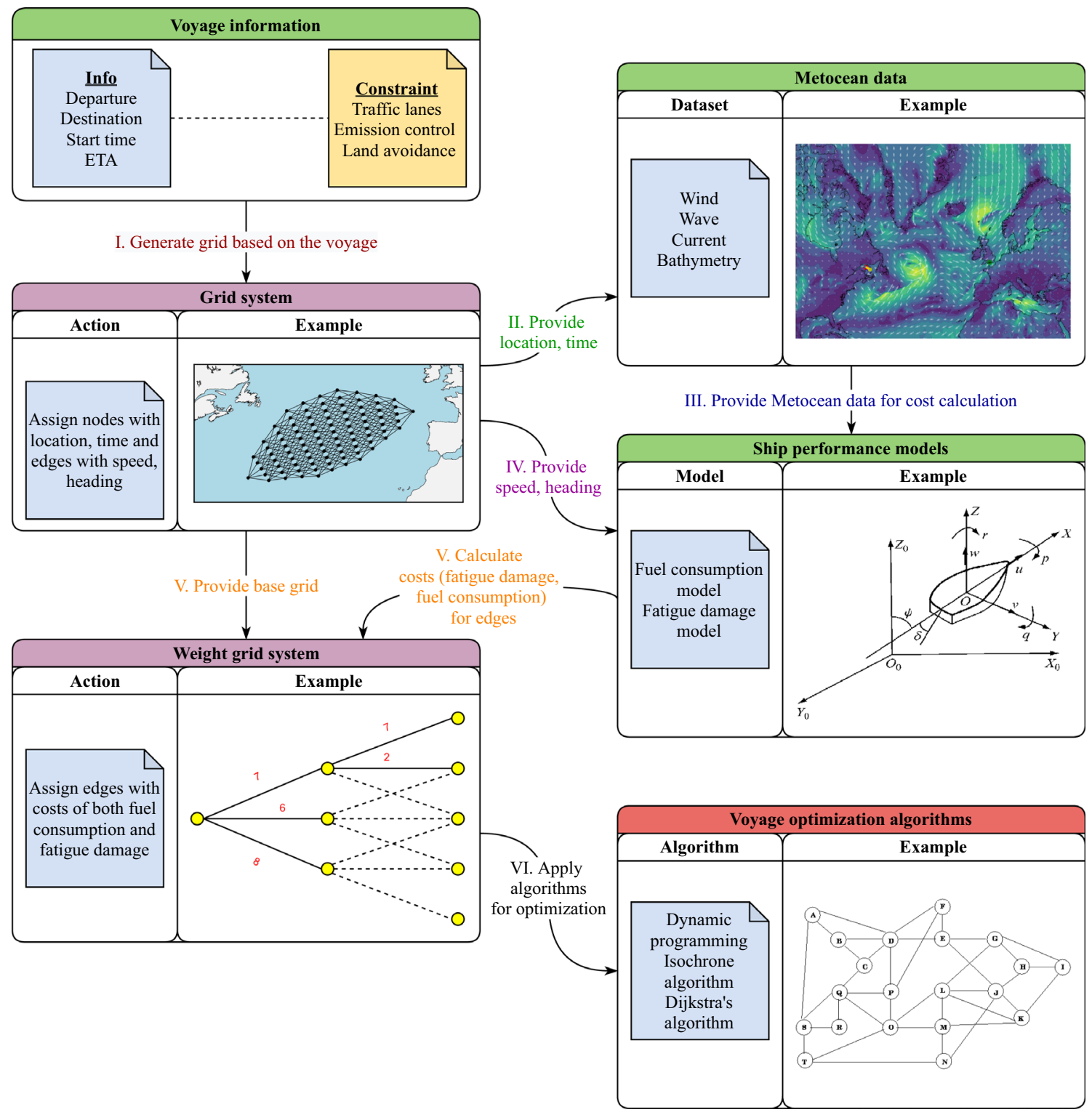

Fig. 9 A typical workflow of the voyage optimization process concerning various objectives, such as minimum fuel consumption, lowest fatigue damage and ETA, etc

route containing a series of waypoints $\overrightarrow{\boldsymbol{P}}$ and the associated operational control sets $\boldsymbol{U}(\overrightarrow{\boldsymbol{P}})$ that will lead to the minimum/ maximum value of $J$ by encountering proper metocean conditions $\boldsymbol{W}(\overrightarrow{\boldsymbol{P}})$.

Many optimization algorithms are available for the ship voyage planning purpose in the maritime community. They are normally categorized into deterministic algorithms and stochastic algorithms. The deterministic algorithms are still the most widely used in the shipping market, considering the efficiency of the algorithms/methods. The most common algorithms are the so-called Isochrone method, 2D and 3D dynamic programming methods, and Dijkstra's methods, in addition to the shortest route sailing known as the great circle routes [37]. The isochrone method was first proposed by James [38] to find the minimum time route by optimizing ship heading under fixed sailing speed. It was modified by Hagiwara [39] to add various functions, such as the expected time of arrival and voluntary speed reduction for more practical voyage optimization. The dynamic programming method proposed by Bellman [40] was also utilized to develop ship voyage optimization systems, such as Chen [41] developed 2D dynamic programming method with fixed speed or power setting along a voyage, and Shao et al. [42] and Zaccone et al. [43] developed 3D dynamic programming methods to optimize both a ship's 
sailing course and speeds along the voyage. Some recent development focus on Dijkstra's algorithm [44], such as in Böttner [45], Skoglund et al. [46], and Wang et al. [35] who proposed a scheme for applying Dijkstra's algorithm into a three-dimensional voyage optimization problem to allow multi-objective global voyage optimizations. Some of the methods used in this study are listed in Table 2 and will be further explained in the following section.

\subsection{Cost functions for minimum fuel and damage optimization objectives}

Normally, different cost functions are needed for various optimization objectives in the voyage planning process. In this study, two objectives are considered to investigate their impact on a ship's long-term wave statistics, i.e., minimum fuel consumption and lowest fatigue damage accumulation, while the sailing time along each voyage (ETA) is set to be the same as the actual sailing route.

For the voyage optimization aiming at minimum fuel consumption, the cost function $f_{\text {c_fuel }}$ to estimate a ship's fuel consumption under various operational and environmental condition $\boldsymbol{U}, \boldsymbol{W}$ is given by:

$f_{\text {c_fuel } 1}=R_{\text {T OT AL }} \cdot V \cdot \mathrm{S} \mathrm{F} \mathrm{OC} \cdot \eta_{\mathrm{p}}$,

where $R_{\text {TOTAL }}=g\left(H_{\mathrm{s}}, T_{z}, \theta_{\text {w a v }}, V_{\mathrm{c}}, \theta_{\mathrm{c}}, V_{\mathrm{w}}, \theta_{\mathrm{w}, \ldots}, V, \theta_{\mathrm{S}}\right)=$ $g(\boldsymbol{W}, \boldsymbol{U})$. The total propulsion efficiency $\eta_{\mathrm{p}}$, and the specific fuel consumption $S F O C[\mathrm{~g} / \mathrm{kWh}] . R_{\text {TOTAL }}$ represents a ship's total resistance consisting of calm water resistance $R_{\mathrm{CALM}}$, added resistance due to wave $R_{\mathrm{AW}}$ and wind $R_{\mathrm{AA}}$. The total resistance is a function of the encountered metocean conditions $\boldsymbol{W}$ and operational conditions $\boldsymbol{U}$. The flowchart for such a modeling is presented in Fig. 10, which describes the procedures to estimate a ship's fuel consumption for a given speed over ground $V_{\mathrm{OG}}$ when encountering various metocean environments. For the voyage optimization, the semi-empirical formulas provided in, e.g., ISO [47] and ITTC [48], are used to estimate the fuel cost function $f_{\mathrm{c}_{-} \text {fuel }}$.

Table 2 Various objectives by specific voyage optimization methods investigated in this study

\begin{tabular}{llll}
\hline Optimization methods & ETA & ETA + Fuel & ETA + Fatigue \\
\hline $\begin{array}{l}\text { Shortest distance with fixed } \\
\text { speed }\end{array}$ & $\mathrm{X}$ & & \\
$\begin{array}{l}\text { 2D Dijkstra (dynamic program- } \\
\text { ming) }\end{array}$ & $\mathrm{X}$ & $\mathrm{X}$ \\
3D Dijkstra's method & $\mathrm{X}$ & $\mathrm{X}$ \\
$\begin{array}{l}\text { Actual sailing (isochrone } \\
\text { method) }\end{array}$ & $\mathrm{X}$ & \\
\hline
\end{tabular}

$\mathrm{X}$ : objectives and voyage optimization methods in this study
The cost function of fatigue damage accumulation $f_{\text {c_damage }}$ depends on the encountered wave condition $\left[H_{\mathrm{s}}, T_{z}\right]$ and ship operational conditions $[V, \theta]$, where $\theta$ is defined as the relative heading angle between the wave direction $\theta_{\text {wave }}$ and ship heading $\theta_{S}$. For one waypoint, it is assumed that the operational conditions are kept the same as the ship reach to the next waypoint. The corresponding wave environments can be extracted based on its sailing time. For the voyage optimization aiming at lowest damage accumulation along each voyage, the cost function $f_{\text {c_damage }}$ to estimate a ship's fatigue damage accumulation under $\boldsymbol{W}, \boldsymbol{U}$ is denoted as:

$f_{\text {c_damage }}=\psi\left(H_{\mathrm{S}}, T_{\mathrm{z}}, \theta_{\mathrm{w} \text { a v } \mathrm{e}}, V, \theta_{\mathrm{S}}\right)=\psi(\boldsymbol{W}, \boldsymbol{U})$.

The procedures to estimate the cost function of fatigue damage in Eq. 13 are briefly presented in Fig. 2. In this study, the spectral fatigue model as in Eq. 7 is employed to estimate the fatigue damage accumulated along two adjacent waypoints with encountered metocean conditions $\boldsymbol{W}$ and operational conditions $\boldsymbol{U}$. The formulas in the cost function to estimate fatigue damage are given in Sect. 2.1.

Table 2 presents various objectives for a ship's voyage planning and corresponding voyage optimization methods used in this study. For the two-dimensional voyage optimizations, the dynamic programming method and the Dijkstra's method give the same results. Different voyage planning methods (with/without optimizations) may recommend different ship routes, especially for sailing in harsh metocean environments. It means that the encountered wave statistics might also be different from each other, and eventually different from their original design wave conditions.

\section{The case study and full-scale measurements}

To study the impact of voyage optimization-aided ship operations on the long-term statistics of wave environments encountered by ships, 3 years of full-scale measurements from a 2800TEU container ship are used for the following analysis. This case study container ship was also equipped with a so-called hull-monitoring system, which measured the ship's operating-related parameters, such as position, speed, heading, pitch and roll motions, and the real-time structural stresses. The full-scale measurements are available from 2007 to February 2010, and a total of 62 complete sailing voyages were selected from all the measurements. The ship was operated in the North Atlantic for transportation between Europe and North America. All the sailing waypoints along these measured voyages are presented in Fig. 11, where the sailing routes have been divided into westbound and eastbound voyages, with the summer and winter sailing seasons. 


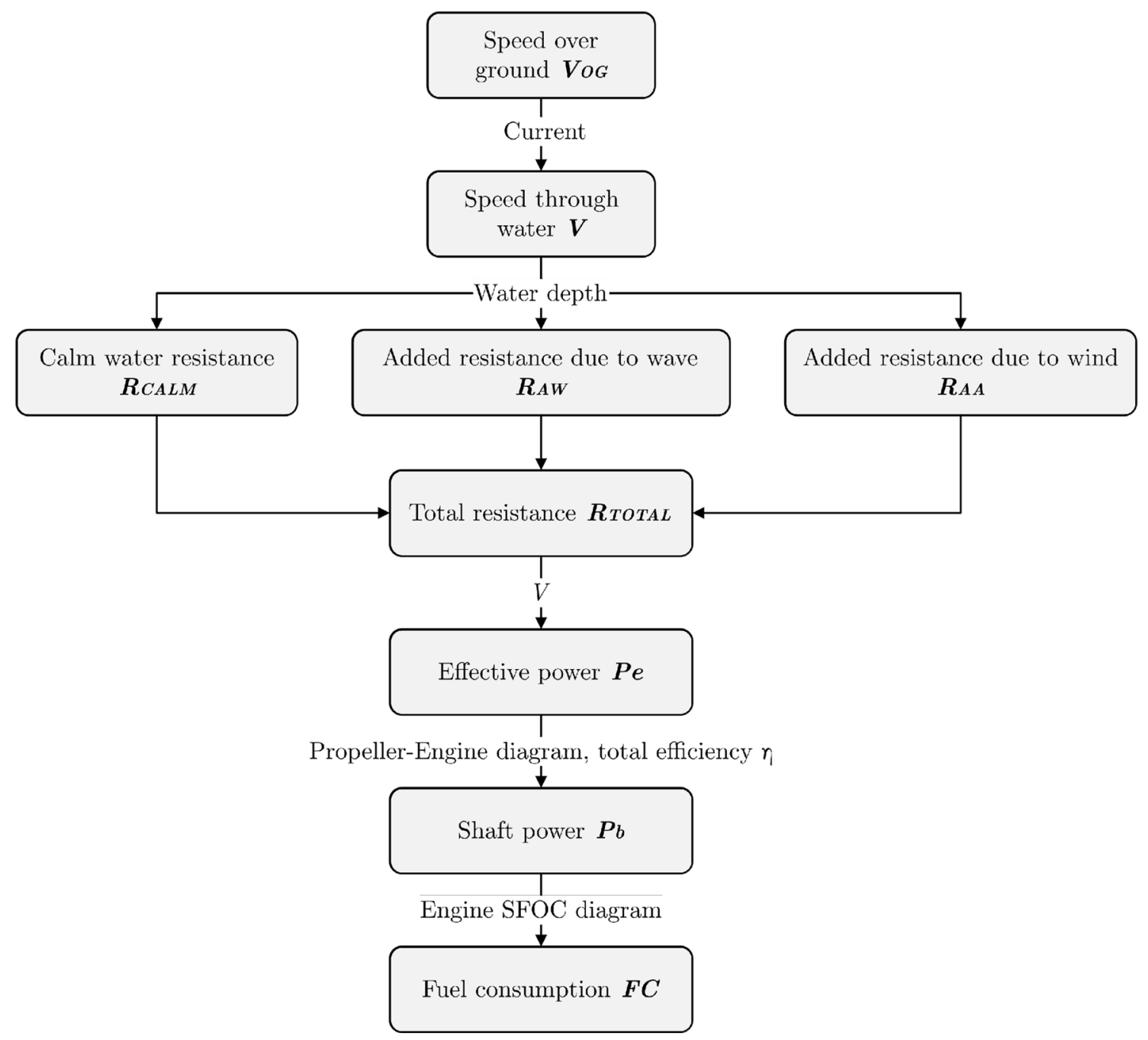

Fig. 10 Ship speed-fuel performance prediction flowchart for a voyage optimization [47]

It should be noted that this container ship was also installed with an old conventional weather routing system using the so-called Isochrone method for voyage optimization, to guide the ship's navigation to avoid severe wave environment conditions. As is shown in Fig. 11, the variation of sailing routes in the same direction at the same seasons indicates the influences of voyage optimization methods on the ship's actual navigations. Herein, the measured voyages are called the actual routes. To simplify the voyage optimization process and extraction of metocean conditions from the hindcast database, only waypoints located in the open sea, as shown in Fig. 11, are used in the analysis.

\subsection{Transfer function RAOs for fatigue assessment}

For the voyage optimization in terms of lowest fatigue damage accumulation, the models to describe the fatigue damage accumulation of the case study ship should be provided.
As in Fig. 2, it is necessary to give the transfer function or response amplitude operators (RAOs) of the local structural stresses, i.e., $H_{\sigma}(\omega \mid V, \theta)$, for the fatigue assessment as a cost function. To get the RAOs, wave bending moments are first estimated by the hydrodynamic analysis based on a 2D potential theory, where the ship is modeled by 20 strips [24]. For this container ship, only one loading condition, i.e., the full-loaded condition, is considered in the hydrodynamic analysis to get the wave loads applied to the ship hull. Then, the global hull girder stresses are computed by the beam theory. Finally, the RAOs of the local stresses is calculated by multiplying the girder stresses by a stress concentration factor (SCF), which is assumed to be 2 for the fatigue analysis in this study.

Some examples of the calculated RAOs of structural stress in the upper deck area (midship section of the ship) are presented in Fig. 12, which shows the effects of heading angles and sailing speeds on RAOs of the structural 

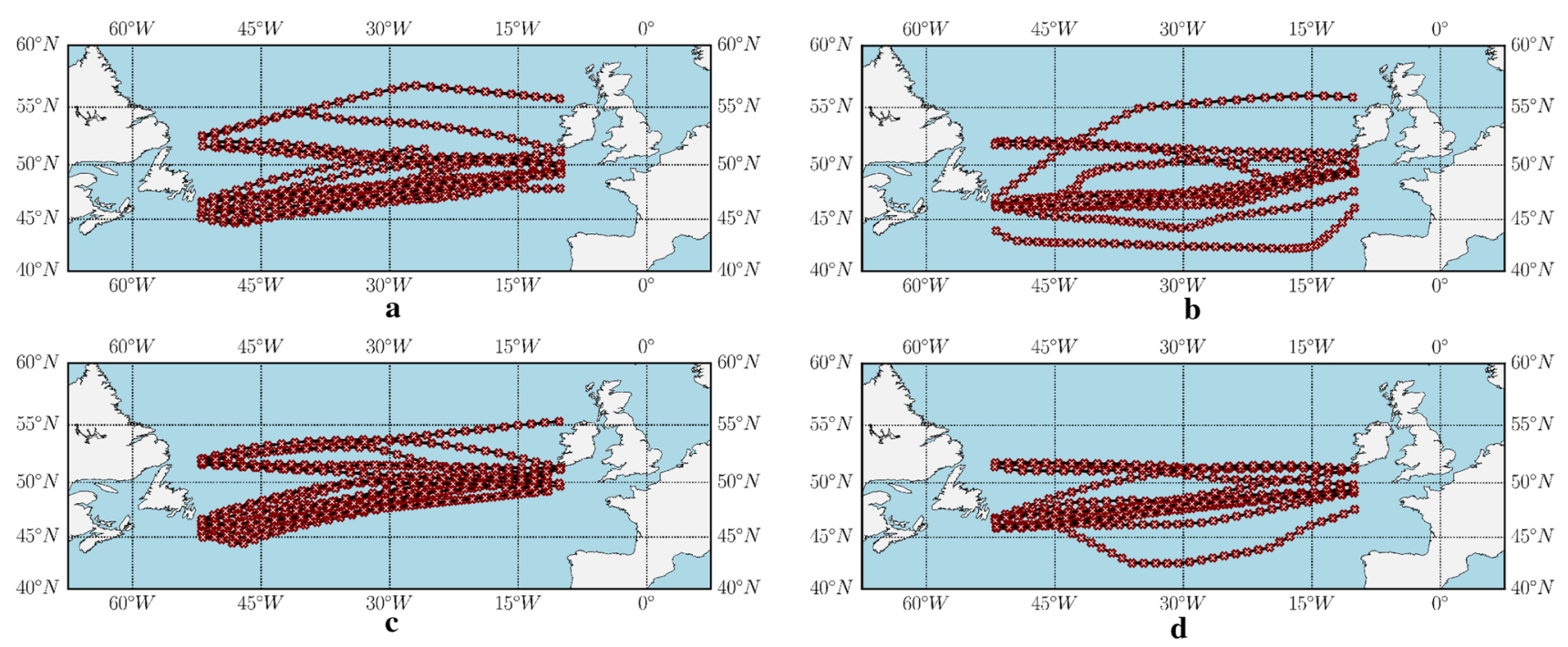

Fig. 11 The case study voyages in the open sea from the 2800TEU container ship, for a westbound summer sailing, b westbound winter sailing, c eastbound summer sailing, and $\mathbf{d}$ eastbound winter sailing
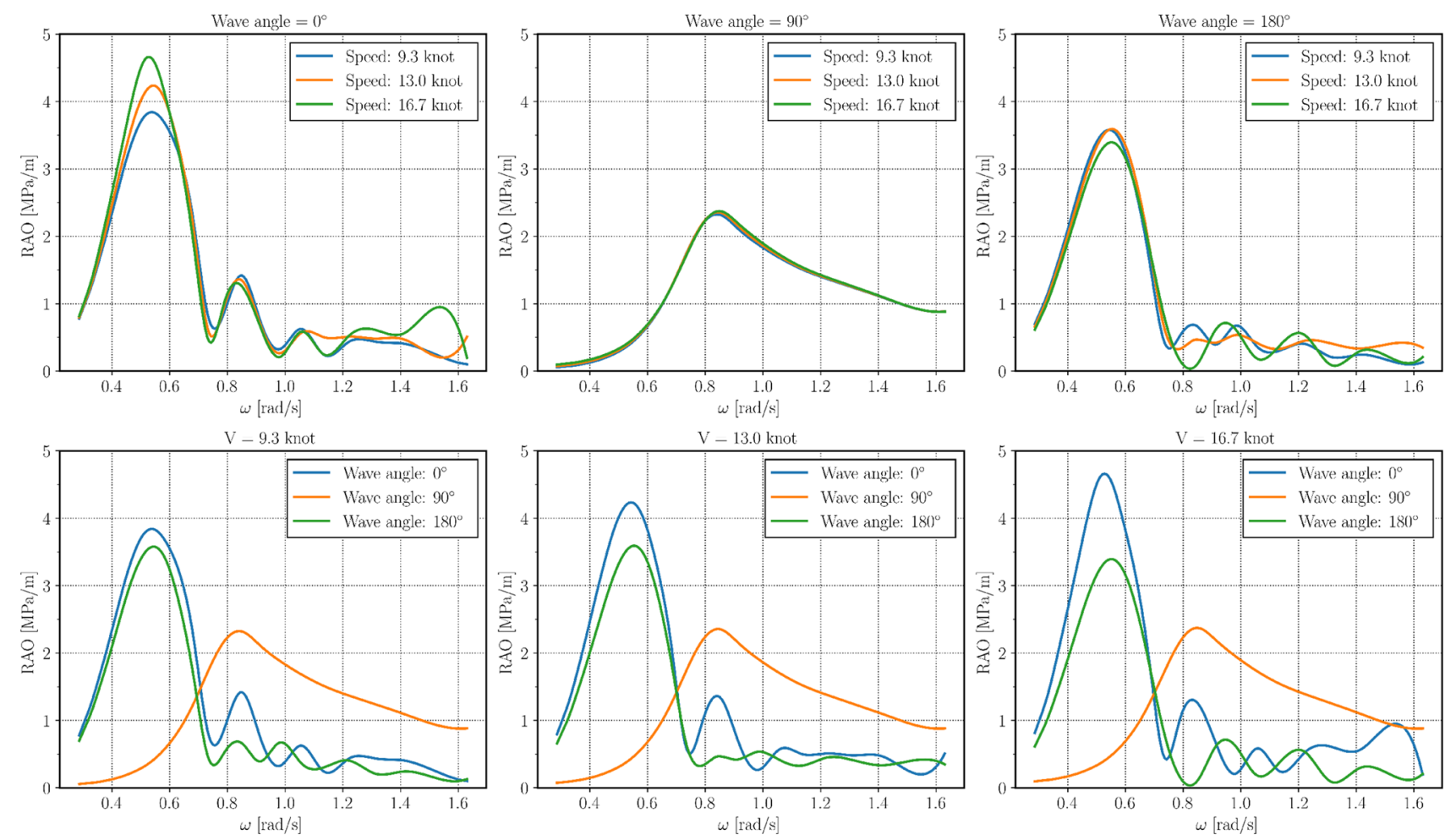

Fig. 12 The transfer function (RAOs) of stresses in the deck longitudinal stiffener of the container ship structures, where $\omega$ stands for the angular frequency of regular waves within the RAOs $H_{\sigma}(\omega \mid V, \theta)$

stresses. The RAOs are more sensitive to the variation of the relative wave heading angles rather than a ship's sailing speeds. Noted that for the case study ship sailing in the North Atlantic, there is not so much optimization margin of wave heading angles, since the storms are always blowing from the west to the east, and relative wave headings are rather stable for sailing in one voyage. One may expect more variation of fatigue damage accumulation if a ship is sailing in other ocean areas, and her voyage planning is performed by various optimization methods. 


\subsection{Validation of RAOs and the spectral method by rainflow counting method}

The stress transfer functions, i.e., RAOs presented in Fig. 12, and the spectral method presented in Fig. 2, are used for the voyage optimization and following fatigue damage analysis. To ensure the accuracy of the applied spectral fatigue assessment method, it is calibrated by the rainflow counting method based on the stress measurements onboard the ship. One example of the measured stress during the voyage 200804-01 is presented in Fig. 13, where the mean stresses are set to be zero. The fatigue damages accumulated along every voyage during the sailing time in the first half-year of 2008 are estimated and compared in Fig. 14. First, the fatigue damages are estimated by the rainflow counting method based on the stress measurements, and they are used as references for the calibration of the spectral method. Second, the spectral method in Eq. 7 is used to estimate the damages, but the spectral moments in Eq. 7 are estimated from the stress measurements, as well. It means that the RAOs are not used in the fatigue assessment. As shown in Fig. 14, the measured structural stress-based spectral method always gives larger damages than the rainflow damage, i.e., approximately $30 \%$ overestimation. This is also expected, since the actual stresses are not narrow-band processes as derived in Eq. 7, which can overestimate the fatigue damages.

However, the continuous overestimation will not affect the voyage optimization in terms of lowest damage, because the optimization process simply compares the relative damages to pick up the "best" route. Finally, the entire process presented in Fig. 2 is used for the fatigue assessment of each voyage. First, the wave environments along the voyages, i.e., a series of $\left[H_{\mathrm{s}}, T_{z}\right]$, are extracted from the ECMWF ERA5 hindcast database [33]. The stress RAOs for each sea state

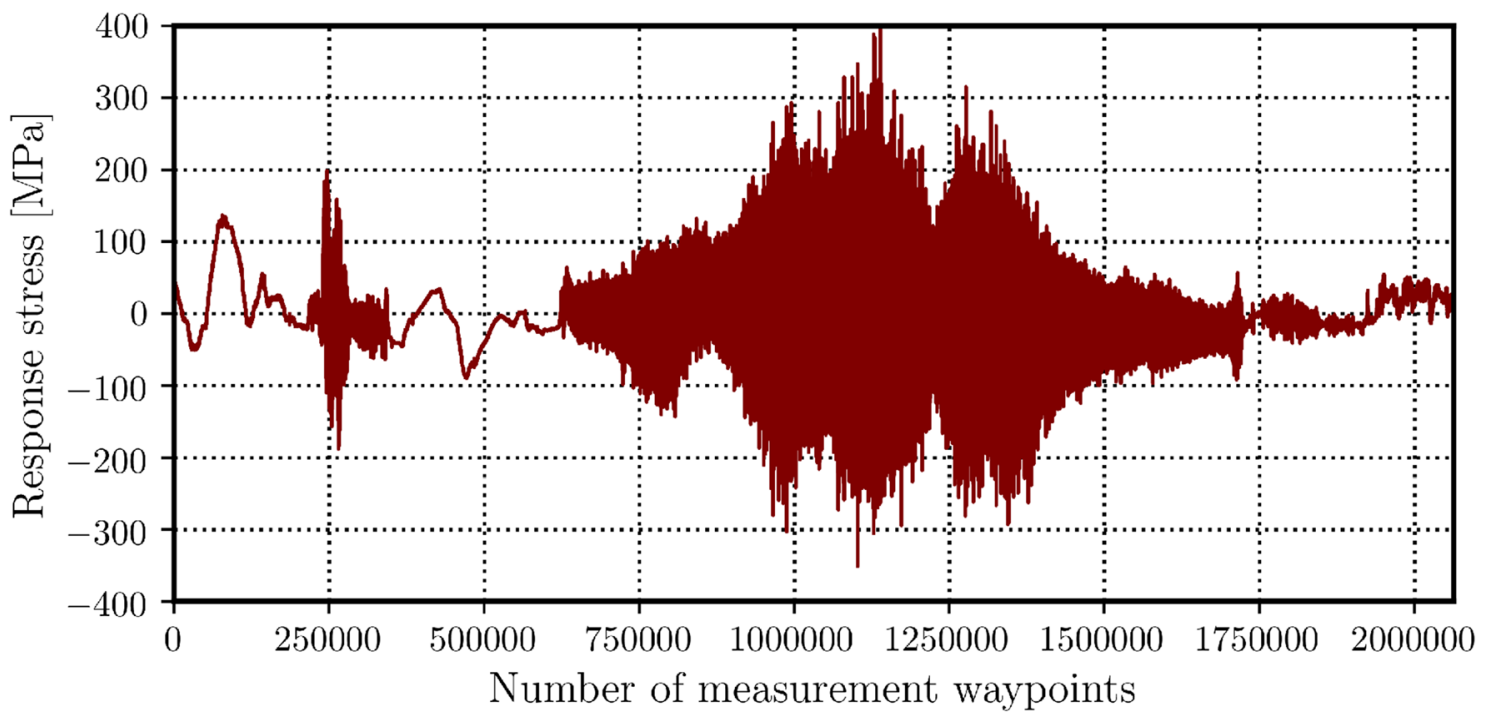

Fig. 13 Stress measurements along an example voyage 2008-04-01 (sailing from 2008-03-21 to 2008-04-01). The mean stress is set to 0

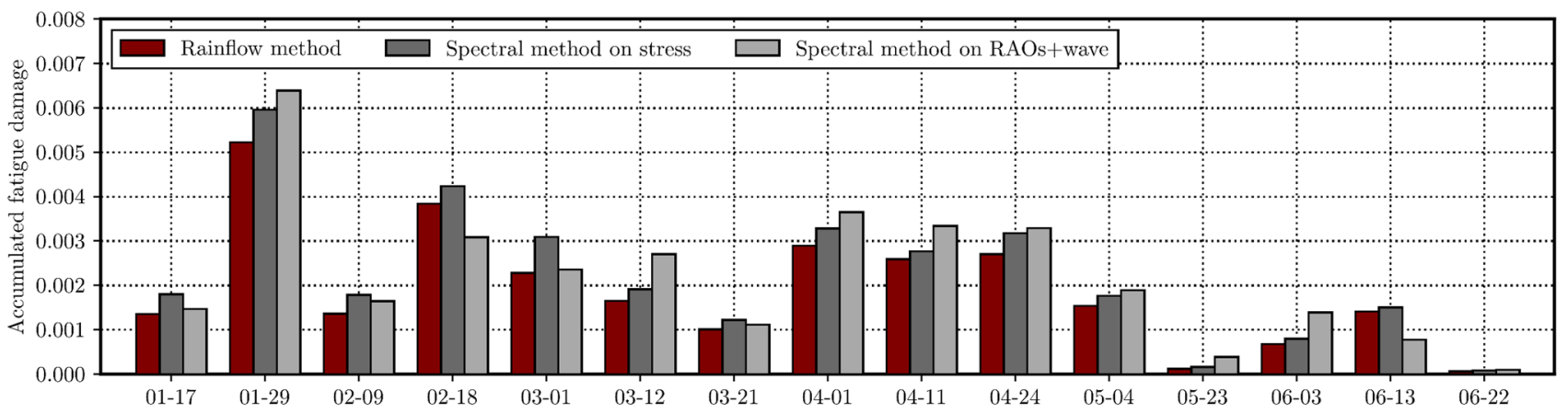

Fig. 14 Fatigue damage accumulated along each voyage in the first half-year of 2008 estimated by the rainflow method, the spectral method based on the measured stresses, and the spectral method based on the stress computed from the estimated RAOs in Fig. 12. The ticks in the $x$-axis represent the name, i.e., the arrival date, of those measured voyages 
are estimated to get the $H_{\sigma}(\omega \mid V, \theta)$ in Eq. 4 and the corresponding spectral moments. Then, the fatigue damage for each sea state is estimated by the spectral method in Eq. 7. Due to uncertainties in the RAOs analysis and the description of actual wave spectrums, a calibration factor is used to scale the total damage equivalent to the stress-based spectral method as in Fig. 14. Even though there are some fluctuations of fatigue damages for each voyage estimated between the two spectral methods, the small difference in the estimation of fatigue damage accumulated along each voyage may mean that from the long-term perspectives, this method can work well to reflect the trend/characteristics of damage accumulation when a ship is encountering various metocean environments. Therefore, the spectral method with RAOs and wave environments as inputs is capable for consider damage accumulation in a ship's voyage optimization process.

\subsection{Observed wave statistics compared with DNV GL guidelines}

During the measurement campaign from 2007 to 2010 when this container ship was sailing in the North Atlantic, the weather routing system used by the onboard seafarers was mainly focusing on how to avoid harsh sea environments and how to reach to the destination on time (ETA), since the fuel and emission concerns were not too much emphasized during that period. One could expect that the longterm wave statistics should be still in line with that provided by classification guidelines. To further quantify the factor, the wave environments along the measured voyages are extracted from the ERA5 hindcast dataset. The wave scatter diagram is built using the extracted hindcast sea states. It is then compared with the wave scatter diagram provided by DNV GL guidelines for North Atlantic sailings in Fig. 15. It shows that under the help of the onboard old weather routing system, the container ship avoided some extremely harsh sea conditions compared to the DNV GL guideline, i.e., less sea states with $H_{\mathrm{s}}$ larger than $8 \mathrm{~m}$. Obviously, it might be simply due to the relatively short measurement periods ( 3 years in comparison with the 25 years design life from the DNV GL guideline). This factor will be further discussed in the following analysis, especially for the voyage optimization of westbound voyages. For the moderate sea states, the "observed" wave environments move to the upwards and rightwards of the wave scatter diagram, in comparison with the wave scatter diagram provided by the DNV GL guideline. There are more sea states with $H_{\mathrm{s}}$ less than $2 \mathrm{~m}$ in the DNV GL diagram. The sea states with $H_{\mathrm{s}}$ between 1.5 and $4.5 \mathrm{~m}$ have the highest probability of occurrence.

\section{Influence of voyage optimization on wave statistics and fatigue design}

Ship operations aided by voyage optimization systems can easily avoid harsh sea environments to ensure ship safety and less fuel consumption. Dependent on ship types/sizes and utilized voyage optimization methods, the encountered wave environments may differ significantly, especially in comparison with the original design conditions. In the following analysis, various voyage optimization methods are implemented to estimate optimal ship routes for the above container ship with respect to different optimization objectives. For the comparison purpose, the sailing time ETA (departure and destination times) is set the same as the measured voyages. Four various voyage planning methods are used for the comparison purpose, i.e., the actual sailing from measurements, the great circle sailing, voyage optimization for minimum fuel consumption, and voyage optimization

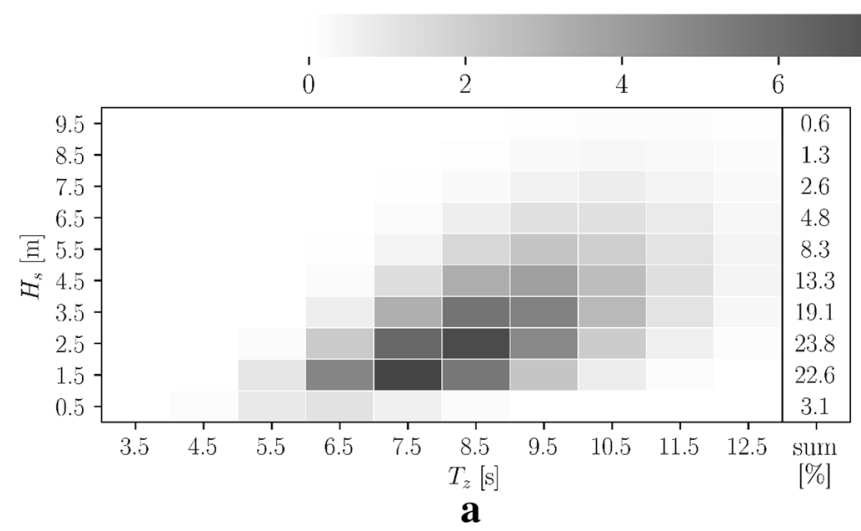

Fig. 15 Comparison of wave scatter diagram between a DNV GL guidelines for the North Atlantic sailing [32] and b observed wave environments from the case study container ship during the 3 -year
Probability of occurrence [\%]

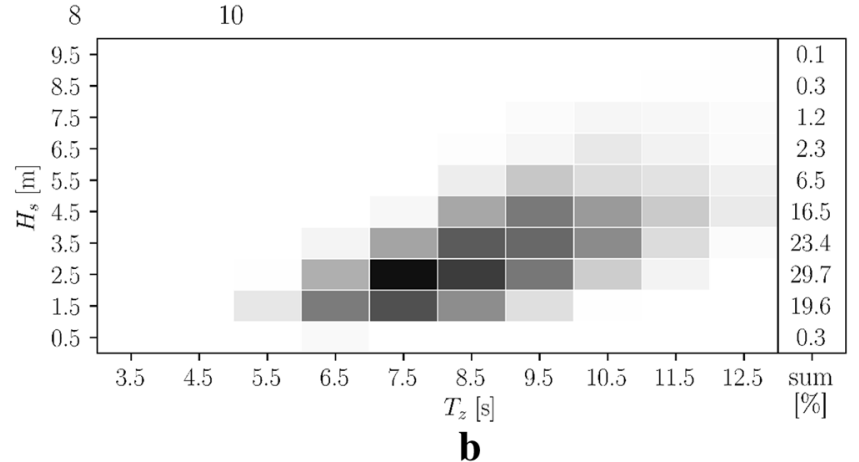

measurement campaign. NB: the color bar presents the probability of the occurrence of certain wave ranges 
for lowest fatigue damage accumulation, respectively. The method for the voyage optimizations is a 3D Dijkstra's Algorithm (3DDA) as proposed in [35]. The influence of voyage optimization-aided ship operations on both short-term wave environments (individual voyage) and long-term wave statistics (sailing during the 3 years of measurement campaign) is also investigated. Furthermore, the benefit of using the four voyage optimization methods on the ship's fatigue life extension is also compared.

\subsection{Impact of short-term encountered wave environment from voyage optimizations}

To study the impact of ship operations aided by various voyage optimization methods on the short-term wave environments encountered by ships, four voyages named as 200907-28, 2008-03-08, 2009-07-13, and 2009-01-18 (the date is the arrival date of each voyage) are chosen for the following analysis. They are selected to represent all sailing scenarios in the North Atlantic, i.e., including the westbound summer, westbound winter, eastbound summer, and eastbound winter, respectively. The planned routes/trajectories of the four case study voyages from the four optimization methods are presented in Figs. 16, 17, 18 and 19 (left plots), respectively. The encountered wave environments denoted by the significant wave height $H_{\mathrm{s}}$ along these optimized routes are presented in the right plots.

As shown in Fig. 16, the calmest wave environments was encountered along the route optimized by the 3DDA method in terms of minimum damage. The wave environments encountered along the route optimized in terms of minimum fuel are a bit calmer than the actual sailing conditions. The actual sailing was not well optimized, because its sailing distance is a bit longer than the great circle route but encountering similar wave environments. It should be noted that even though the same 3DDA method is used for both the fuel-based and damage-based voyage optimization, a big difference in their encountered wave environment can be observed. The difference is mainly since the fuel-related objective function is more sensitive to speed variation than the damage-related objective function during the voyage optimization process.

Figures 17 and 18 present the results of two typical study cases. The great circle sailing routes are associated with higher wave environments. The fuel-based voyage optimization gives similar wave environment as the actual sailing routes. In addition to the significant wave height $H_{\mathrm{s}}$, the fuel-based 3DDA voyage optimization method can consider the effect of other sea environmental parameters such as heading, speed, wave period, etc., on the ship's
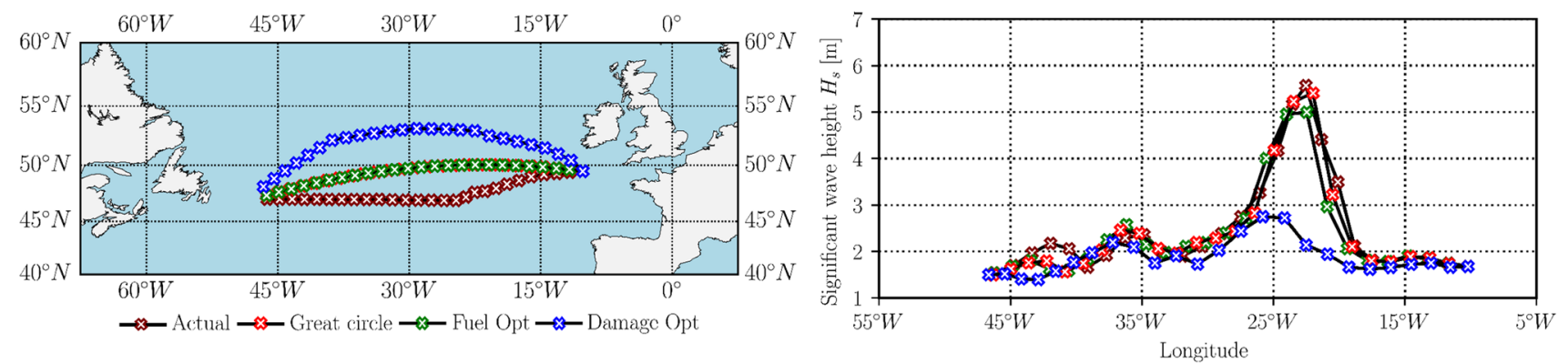

Fig. 16 Optimized ship routes/trajectories (left plot) and encountered $H_{\mathrm{s}}$ (right plot) by various voyage optimization methods for the westbound summer sailing voyage 2009-07-28
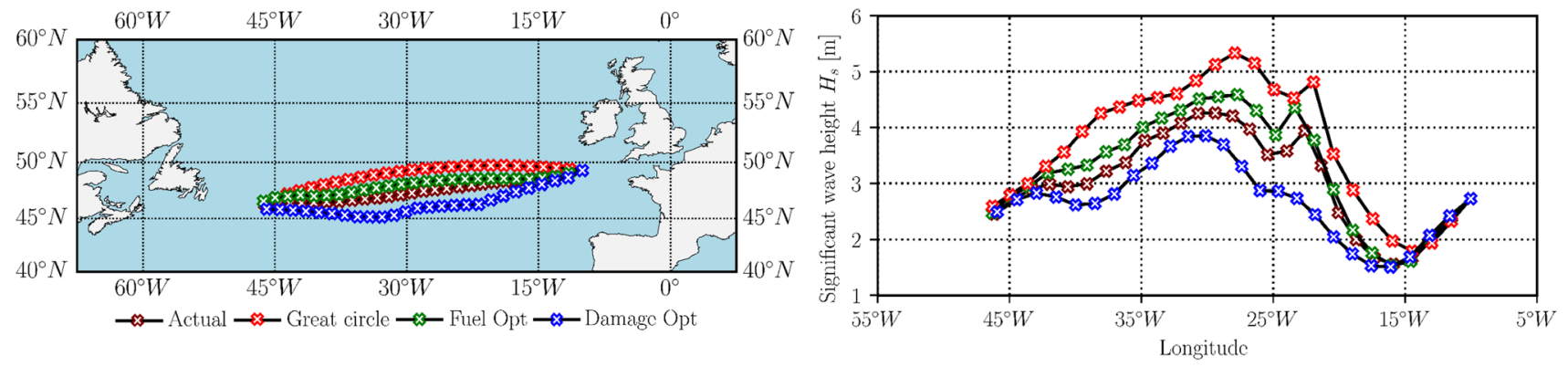

Fig. 17 Optimized ship routes/trajectories (left plot) and encountered $H_{\mathrm{s}}$ (right plot) by various voyage optimization methods for the westbound summer sailing voyage 2008-03-08 

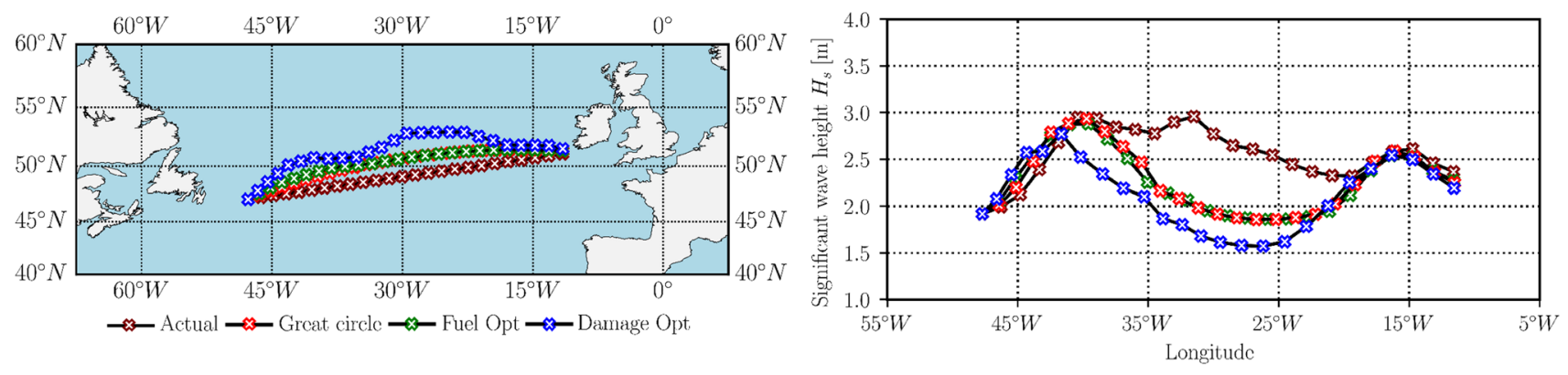

Fig. 18 Optimized ship routes/trajectories (left plot) and encountered $H_{\mathrm{s}}$ (right plot) by various voyage optimization methods for the westbound summer sailing voyage $2009-07-13$
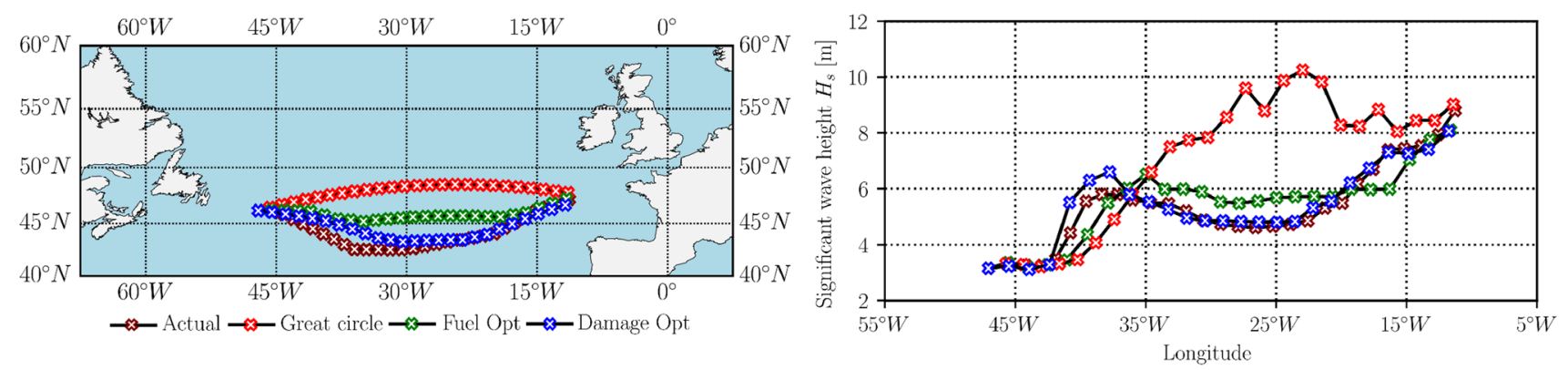

Fig. 19 Optimized ship routes/trajectories (left plot) and encountered $H_{\mathrm{s}}$ (right plot) by various voyage optimization methods for the westbound summer sailing voyage 2009-01-18

fuel consumption along a voyage. The fuel-based voyage optimization can always generate optimal routes with less fuel consumption than the actual sailing routes [35].

For the eastbound winter voyage 2009-01-08 in Fig. 19, if the ship was sailing in their conventional routes, i.e., the shortest distance (great circle) route, very harsh sea environments with $H_{\mathrm{s}}$ more than $10 \mathrm{~m}$ were encountered. Under the aid of an unknown weather routing system, the actual sailing route significantly moved toward the south. Even though long sailing distance is required, the ship avoided majority of the harsh storm. The 3DDA damagebased voyage optimization method suggests a route with trajectory quite similar as the measured route, and the encountered wave environments are also close. By better adjusting the ship's speeds and headings along the optimized route, the damage-based voyage optimization can reduce the damage by about $17 \%$, even though the ship encounters a bit higher waves than the measured. The fuelbased voyage optimization does not suggest a route toward as south as the actual route, but it still manages to avoid the largest storm conditions. Even though the fuel consumption along the fuel-based optimization route is lower than the measured route, its damage accumulation is much higher than the damage estimated from the actual route.
Table 3 Ship fatigue damage accumulated in the considered individual voyage

\begin{tabular}{lllll}
\hline Voyage & Actual & Great circle & Fuel optimization & $\begin{array}{l}\text { Damage } \\
\text { optimiza- } \\
\text { tion }\end{array}$ \\
\hline $2009-07-28$ & 0.0029 & 0.0018 & 0.0015 & 0.0003 \\
$2008-03-08$ & 0.0028 & 0.0051 & 0.0032 & 0.0012 \\
$2009-07-13$ & 0.0003 & 0.0003 & 0.0003 & 0.0002 \\
$2009-01-18$ & 0.0017 & 0.0129 & 0.0025 & 0.0014 \\
\hline
\end{tabular}

Finally, after the voyage optimization on each voyage, all the relevant wave environmental parameters, such as significant wave height $H_{\mathrm{s}}$, wave period $T_{z}$ and heading angle, are extracted from those optimized routes, as well as the corresponding sailing speeds. These parameters are input in the spectrum method using RAOs as Fig. 12 to estimate the accumulated fatigue damages along these routes. The results of those damage accumulations are presented in Table 3 . The great circle routes can cause the highest fatigue damage for all the selected voyages, while the damage-based 3DDA voyage optimization leads to the lowest fatigue damages. Even though the fuel-based 3DDA voyage optimization method 
can generate optimal routes always with less fuel consumption than the actual sailing routes. Some optimized routes by this method can cause higher fatigue damage accumulation than the actual routes. On average, at least 50\% reduction of fatigue damage accumulation can be expected if the damagebased 3DDA method is used for the voyage optimizations.

\subsection{All eastbound and westbound sailing in 3 years}

To investigate the sailing direction and seasonal impact on the long-term encountered wave environments and corresponding damage accumulation due to ship operation aided by various voyage optimizations, all the voyages measured during the 3-year sailing in the North Atlantic are categorized into three groups, i.e., summer voyages, eastbound winter voyages, and westbound winter voyages. The statistics of the significant wave height $H_{\mathrm{s}}$ of wave environments encountered along those optimized ship routes are evaluated. The first three moments of $H_{\mathrm{s}}$ are presented in Table 4. For the summer voyages, all different wave statistics are similar due to the overall calm wave environments around these summer voyages. It should be also noticed that the encountered $H_{\mathrm{s}}$ during the summer voyages are much smaller than both eastbound and westbound winter voyages. For the winter voyages, there is a general trend that the eastbound voyages are encountering wave environment with a little lower $H_{\mathrm{s}}$ than the westbound voyages. There is about 2-5\% decrease of $E\left[H_{\mathrm{s}}\right]$ if the 3DDA voyage optimization methods are used in comparison with the actual and great circle sailings. Since the fatigue damage is approximately proportional to $H_{\mathrm{s}}^{3}$ of the encountered wave environments, it is shown that there is $20-30 \%$ reduction of $E\left[H_{\mathrm{s}}^{3}\right]$ caused by the 3DDA voyage optimization methods.

It should be noted that in addition to the $E\left[H_{\mathrm{s}}^{3}\right]$, the heading angles, wave periods, and sailing speeds also have great influence on the final fatigue damage accumulation along those optimization routes. To quantify the impact of voyage optimization-aided operations to the actual fatigue damage (in addition to the basic wave statistics), the fatigue damages accumulated along various voyages within the four voyage groups (eastbound summer voyages, eastbound winter voyages, westbound summer voyage, and westbound winter voyages) are estimated by the method presented in Sect. 2.1. Since the number of voyages in the four voyage groups is different, average fatigue damage accumulation along each voyage for each group is estimated and shown in Fig. 20. It is shown that the fatigue damage accumulated along the summer voyages is much lower than winter voyages. Even though the wave statistics between westbound winter voyage and eastbound winter voyages are quite similar as in Table 4, the fatigue damages accumulated in westbound winter voyages are much higher than the eastbound winter voyages. For all the voyage groups, the great circle routes always lead to the highest fatigue damage than other voyage planning methods. The difference of fatigue damage accumulation between the actual sailing and the fuel-based 3DDA voyage optimization is very small. However, the damage-based 3DDA voyage optimization method can easily help the ship to reduce her fatigue damage accumulated by more than $50 \%$. Especially, the benefits of ship operation aided by voyage optimization in terms of calm encountered waves and less fatigue damage accumulation are more pronounced for the westbound winter voyages.

\subsection{Impact on long-term wave environments and fatigue design}

For a ship's fatigue design, the long-term wave statistics are of the most importance to design the ship structures. It was reported previously that a ship's actual encountered wave
Table 4 The first, second, and third moments of $H_{\mathrm{s}}$ encountered by the subject ship for summer and winter routes

\begin{tabular}{lllll}
\hline Voyage group & Voyage optimization methods & $\begin{array}{l}\text { First moment } \\
\text { of } H_{\mathrm{s}}, E\left[H_{\mathrm{s}}\right]\end{array}$ & $\begin{array}{l}\text { Second } \\
\text { moment of } H_{\mathrm{s}}, \\
E\left[H_{s}^{2}\right]\end{array}$ & $\begin{array}{l}\text { Third } \\
\text { moment of } \\
H_{\mathrm{s}}, E\left[H_{s}^{3}\right]\end{array}$ \\
\hline \multirow{2}{*}{ Summer voyages } & Actual & 2.64 & 7.89 & 26.73 \\
& Great circle & 2.63 & 7.84 & 26.27 \\
& Fuel optimization & 2.61 & 7.77 & 26.18 \\
& Damage optimization & 2.45 & 6.79 & 21.28 \\
Eastbound winter voyages & Actual & 4.20 & 19.48 & 98.9 \\
& Great circle & 4.24 & 20.16 & 108.19 \\
& Fuel optimization & 4.08 & 18.01 & 84.76 \\
& Damage optimization & 3.87 & 16.54 & 77.24 \\
Westbound winter voyages & Actual & 4.22 & 19.67 & 99.95 \\
& Great circle & 4.21 & 19.42 & 95.32 \\
& Fuel optimization & 4.12 & 18.60 & 90.99 \\
& Damage optimization & 3.96 & 17.58 & 85.86 \\
\hline
\end{tabular}




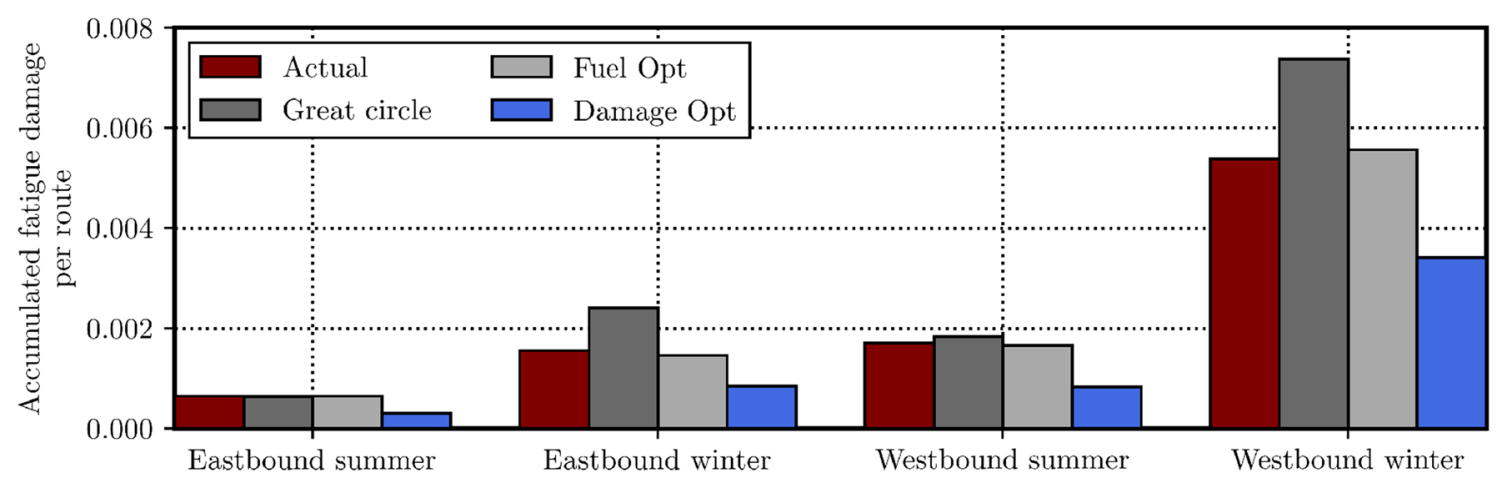

Fig. 20 Average fatigue damage accumulation along each voyage for different voyage groups categorized by sailing directions and seasons

statistics could differ significantly from her design conditions due to various methods used in a ship's navigation. In this study, all 3-year full-scale measurements are used to study the impact of ship operation aided by various voyage optimizations on the long-term wave statistics encountered by ships. First, for all the measured voyages, the four voyage planning methods are used to design the ship's sailing routes. Then, the encountered wave environments, i.e., significant wave height $H_{\mathrm{s}}$ and wave period $T_{z}$, are extracted from those planned routes.

The distribution of $H_{\mathrm{s}}$ extracted from those suggested routes is compared with the distribution of $H_{\mathrm{s}}$ provided by
DNV GL guidelines, as in Fig. 21. As shown, there are more moderate sea states from the actual and planned routes than those obtained from the design guidelines. The probability of larger $H_{\mathrm{s}}$ for the optimized routes is lower than the actual and great circle routes. Specifically, the damage optimization routes have encountered calmer sea states distributed around $2 \mathrm{~m}$, and less severe sea states $H_{\mathrm{s}}$ higher than $4 \mathrm{~m}$, even compared to the fuel optimized routes. It can be explained that the ship's fatigue damage is more sensitive to the harshness of encountered wave environments than the ship's fuel consumption. The damage-based voyage optimization method would recommend a longer distance route with a higher

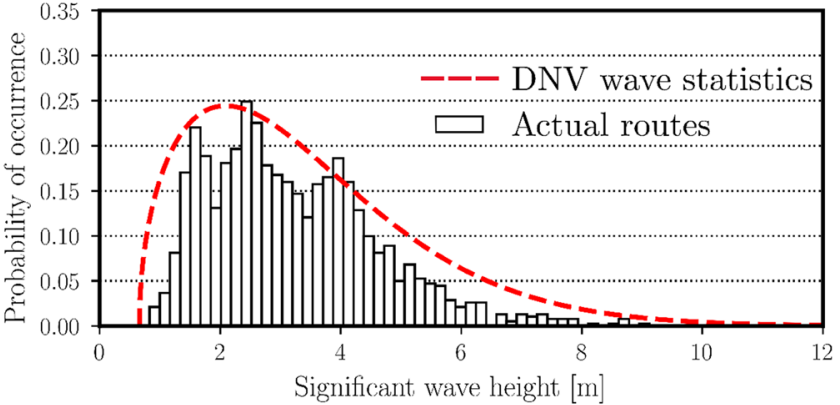

$\mathbf{a}$

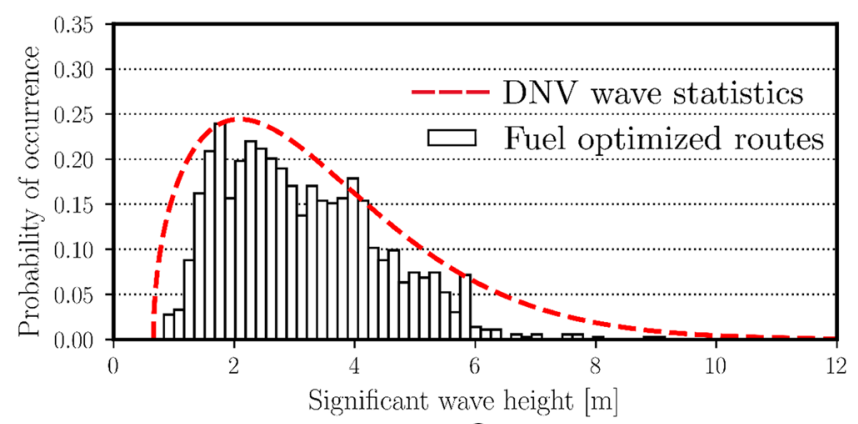

C

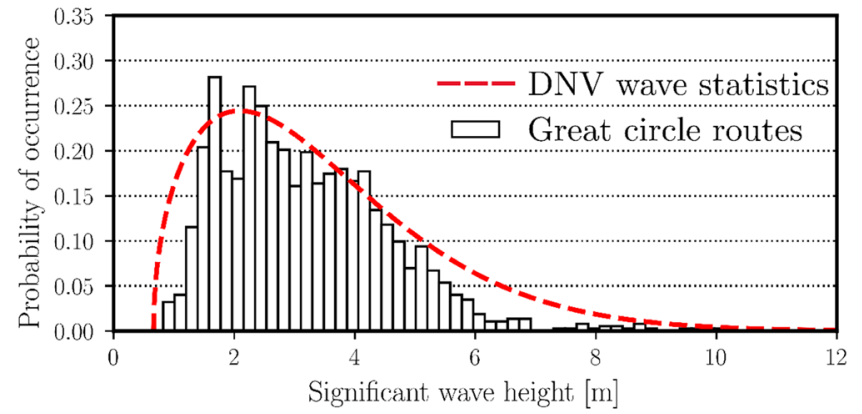

b

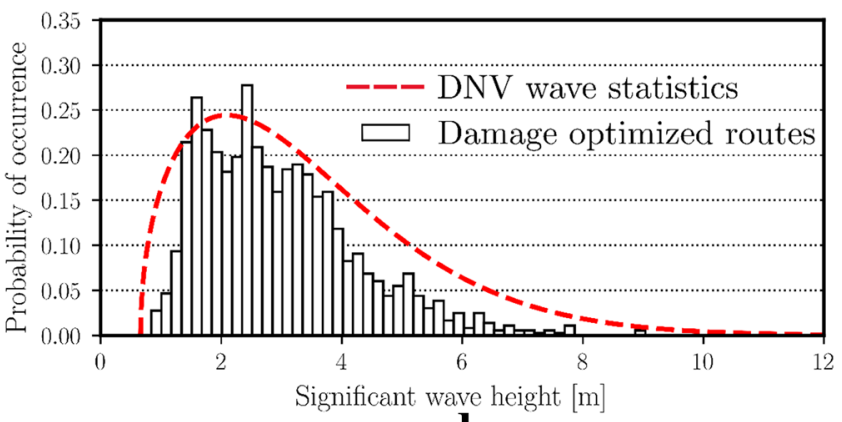

d

Fig. 21 Comparison of probability density function of $H_{\mathrm{s}}$ from DNV GL with the probability histograms of $H_{\mathrm{s}}$ from a actual routes, $\mathbf{b}$ great circle routes, $\mathbf{c}$ fuel-based optimization routes, and $\mathbf{d}$ damage-based optimization routes 
speed to ensure the ETA and minimize the fatigue accumulation in a lower $H_{\mathrm{s}}$ area.

Furthermore, according to the classification guidelines, the significant wave height of $H_{\mathrm{s}}$ is normally assumed to be Weibull distributed. To check the reliability of the Weibull assumption for $H_{\mathrm{s}}$ encountered along those optimized routes, all those $H_{\mathrm{s}}$ are compared in a Weibull plot as Fig. 22, where the straight lines can be recognized as the Weibull fit to $H_{\mathrm{s}}$ observed along with various methods of optimized routes. As shown, the distributions of $H_{\mathrm{s}}$ from great routes, actual routes, fuel-based optimization routes, and damage-based optimization routes obviously have longer tails of $H_{\mathrm{s}}$ less than $1.8 \mathrm{~m}$ compared to the perfect Weibull distributions. The fit has a good match for the significant wave height in the range between 1.8 and $5 \mathrm{~m}$, and as the zoom-in area describes, the minimum damage routes have a high accumulative distribution for the lower $H_{\mathrm{s}}$ span. There is a small discrepancy in the tails of $H_{\mathrm{s}}$ larger than 5 meters.

To predict how various voyage optimization-aided ship operations will affect the long-term wave environments, the fitted Weibull distributions based on the 3 years of measured voyages are used to extrapolate the largest encountered $H_{\mathrm{s}}$ during a period of $1 / 10 / 25$-year service time. The $H_{\mathrm{s}}$ extracted from the actual sailing routes, great circle routes, and damage-based voyage optimization routes are used for the extrapolation purpose. The results of the Weibull extrapolation are presented in Fig. 23, and the maximum $H_{\mathrm{s}}$ encountered during the $1 / 10 / 25$ years' service time from the extrapolation is listed in Table 5. It is obviously shown in Fig. 23 that the Weibull distributions underestimate the encountered $H_{\mathrm{s}}$ in storm conditions for all the voyage planning methods. Table 5 also

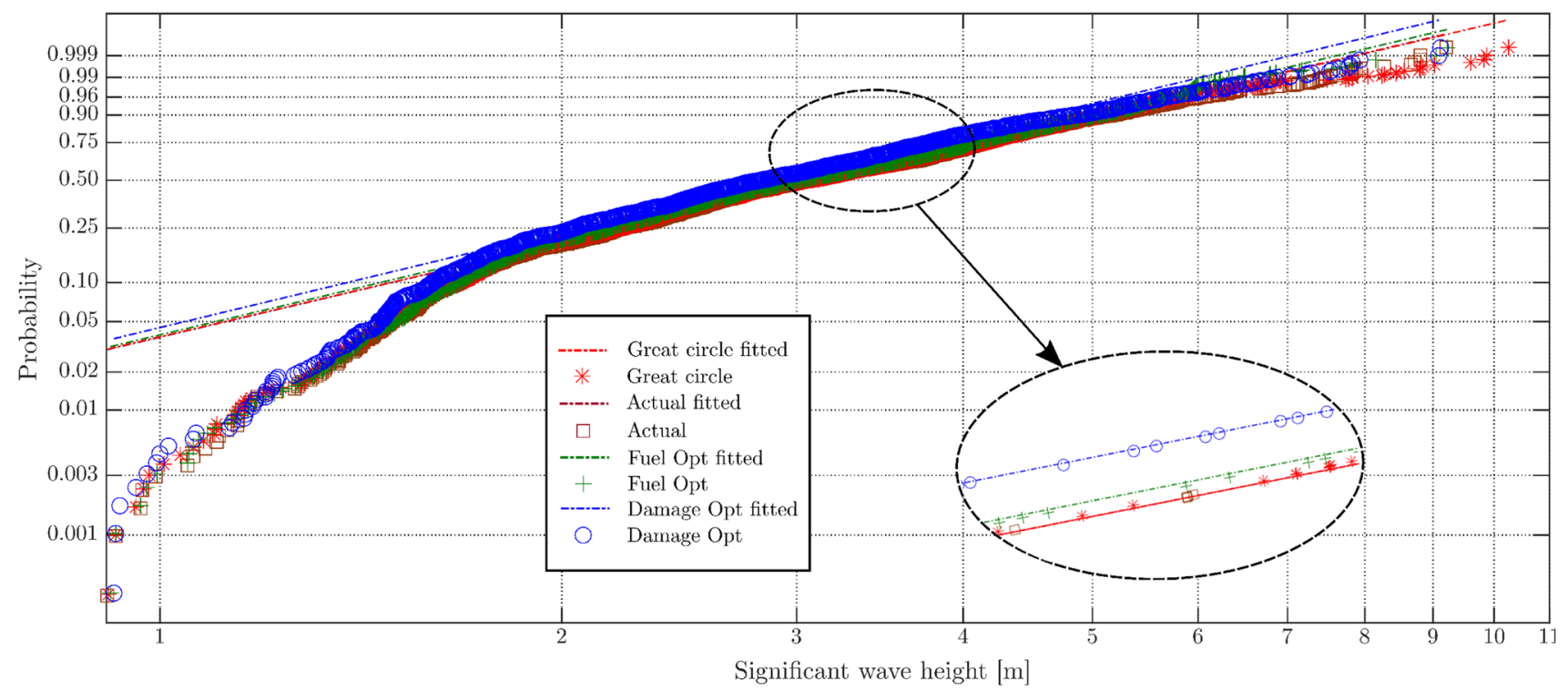

Fig. 22 Weibull probability plots of $H_{\mathrm{s}}$ extracted from routes generated by various voyage planning methods
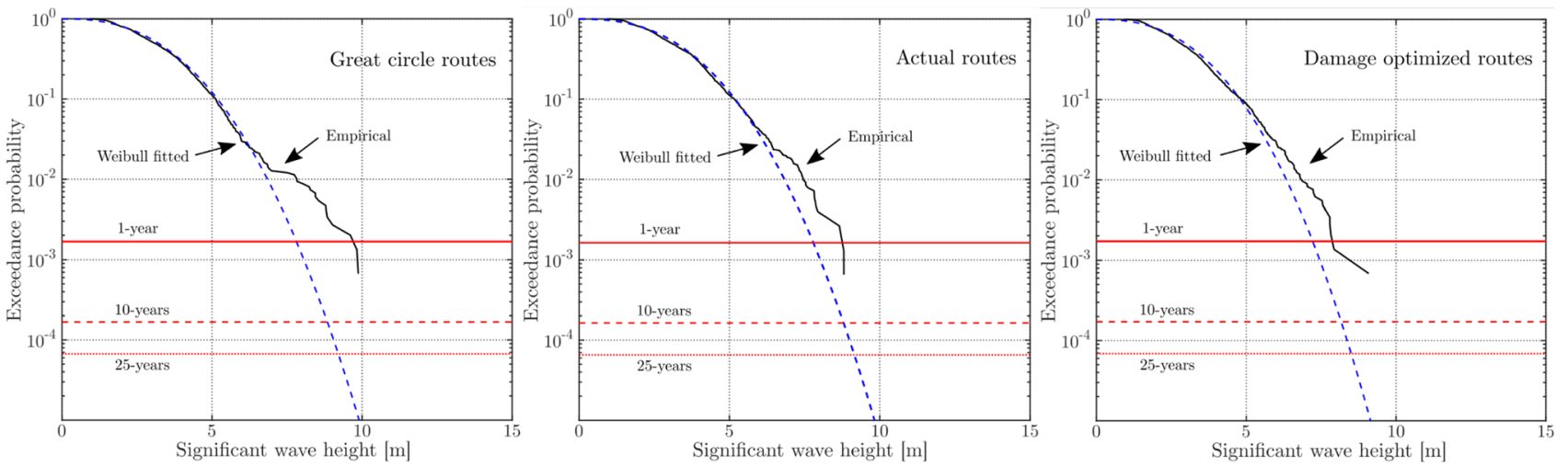

Fig. 23 Extrapolation of maximum $H_{\mathrm{s}}$ encountered during 1-year, 10-year, 25-year sailing for actual routes, great circle routes, and damage optimized routes, based on the Weibull probability fitting method 
Table 5 Extrapolated maximum $H_{\mathrm{s}}$ encountered during 1-year, 10-year, and 25-year sailing time

\begin{tabular}{llll}
\hline Routes & 1 year $(\mathrm{m})$ & 10 years $(\mathrm{m})$ & 25 years $(\mathrm{m})$ \\
\hline Actual routes & 7.8 & 8.8 & 9.1 \\
Great circle routes & 7.8 & 8.85 & 9.2 \\
Damage optimization & 7.2 & 8.1 & 8.5 \\
\hline
\end{tabular}

shows that the damage-based voyage optimization method can significantly reduce the maximum $H_{\mathrm{s}}$ encountered during both 10 -year and 25 -year service. This may also indicate that voyage optimization methods can reduce the possibility of ships encountering large waves in a ship's future service time.

Finally, the fatigue damage accumulation in terms of the 3 years of measurement time is presented in Fig. 24 . The damages are estimated by the presented spectral method with RAOs from Fig. 12. The damage accumulations are estimated for sailing along the actual routes, the great circle routes, the fuel-based optimization routes, and the damage-based optimization routes, respectively. It is observed that the damage accumulated in the great circle routes is nearly two times larger than that accumulated in the damage-based optimization routes. It is also roughly $30 \%$ larger than the accumulated damage along the actual routes and fuel-based optimization routes. The fatigue damage accumulated along winter voyages is increasing dramatically faster than summer voyages. It may happen that most of the fatigue damage is accumulated in one or two winter voyages during 1 year of sailing. Moreover, for a ship with serious fatigue problems, especially in old ships, the damage-based 3DDA voyage optimization method can be effectively used to reduce the damage accumulation in those ship structures.

\section{Conclusions}

According to the noon reports and full-scale measurements from three fleets of container ships, VLCCs, and chemical tankers, those ships' actual operations, such as slow steaming and voyage optimization, etc., have a significant impact on the long-term wave statistics encountered by the ships, in comparison with their design conditions. In addition to the influences on the wave statistics, the change of ship speeds and heading angles in a ship's actual sailing will also lead to different fatigue life from the design. By carefully planning a ship's operations, more calm sea environments can be encountered, and some severe storms can be avoided. For the case study fleet of slow steaming VLCCs, more than $75 \%$ of their service time was spent at sea states with $H_{\mathrm{s}}$ less than $2 \mathrm{~m}$, while less than $1 \%$ of their service time was encountering harsh sea environments with $H_{\mathrm{s}}$ larger than $5 \mathrm{~m}$, in comparison with $60 \%$ and $9 \%$ as provided in the design wave diagram. A similar trend but less significant is also observed in the fleet of slow steaming container ships.

In addition to the operations related to the slow steaming, the full-scale measurements of a 2800TEU container ship also indicate large influences of encountered wave statistics due to actual operational conditions. Since the old conventional weather routing system was used onboard the case study ship to guide her navigation, the encountered severe sea states with $H_{\mathrm{s}}$ larger than $5 \mathrm{~m}$ have been significantly reduced. Furthermore, the wave periods of encountered sea environment are larger than the design wave scatter diagram, leading to lower fatigue damage than the designed.

Various voyage optimization methods are applied for the case study container ship to study both the short-term and long-term impacts on a ship's encountered wave conditions and corresponding fatigue damage accumulations. For the four selected voyages in the North Atlantic, the short-term

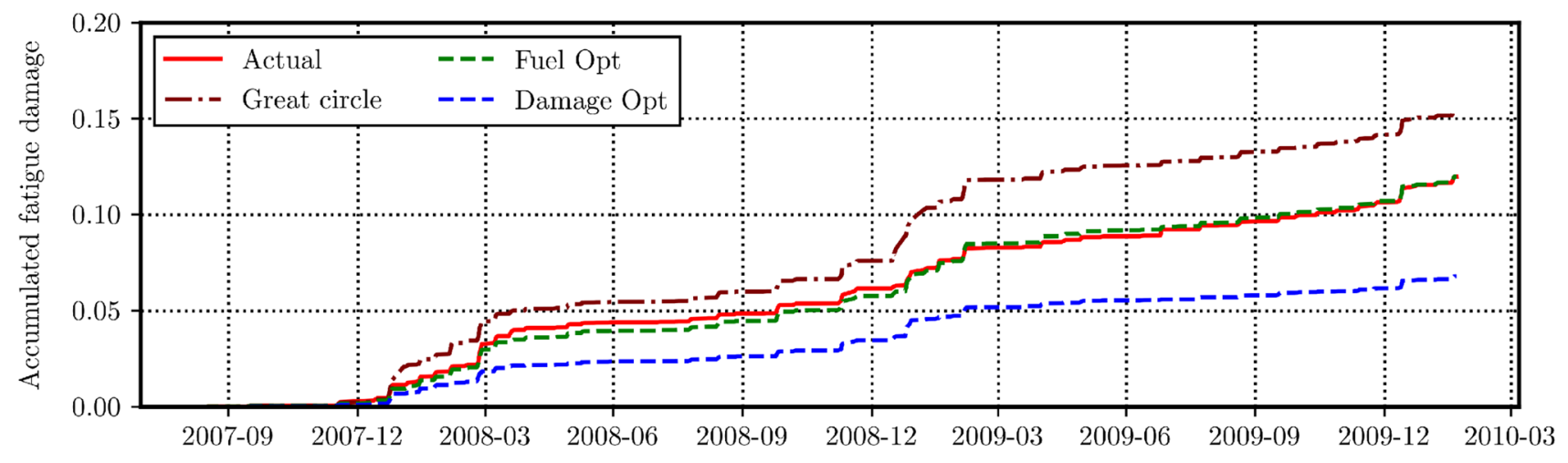

Fig. 24 Fatigue damage accumulated along 3-year measurement campaign estimated by the spectral method, where the encountered wave conditions are extracted along the actual routes, the great cir- cle routes, the fuel-based optimization routes, and the damage-based optimization routes, respectively 
wave environments are significantly reduced using the voyage optimization methods, especially for winter voyages. The maximum encountered significant wave height is dropped by about $50 \%$. The accumulated fatigue damages for these voyages can be easily reduced by $50 \%$ to $90 \%$ through a careful voyage optimization method consider the damage accumulation.

Besides, various voyage planning methods are compared, such as the Isochrone method from actual sailing, Dijkstra's algorithm, Dynamic programming, etc., to study their impacts on wave statistics and fatigue damage. The effects on the winter voyages are more pronounced than the summer voyages. The difference in wave statistics from various optimization methods is about $10-30 \%$, while the difference in fatigue damage is more than $50 \%$. In any cases, the actual sailing will encounter less harsh sea environments when comparing the probability density functions from the classification guidelines. Finally, a good voyage optimization method can greatly help to effectively extend a ship's fatigue life by at least $50 \%$ by recommending appropriate routes, especially for harsh sea environment navigations.

Acknowledgements The authors acknowledge the financial support from the European Commission (Horizon 2020) project EcoSail (Grant number 820593). We are also grateful to the support from the Swedish Foundation for International Cooperation in Research and Higher Education (CH2016-6673), National Natural Science Foundation of China (NSFC-51779202), and ship owners for providing model tests results and related full-scale measurements data. The third author thanks the funding from the European Union's Horizon 2020 research and innovation program under the Marie Sklodowska-Curie (Grant number 754412) and VGR MoRE2020. The authors thank the three anonymous reviewers for their valuable comments, which significantly improve the quality of the paper.

Funding Open access funding provided by Chalmers University of Technology.

Open Access This article is licensed under a Creative Commons Attribution 4.0 International License, which permits use, sharing, adaptation, distribution and reproduction in any medium or format, as long as you give appropriate credit to the original author(s) and the source, provide a link to the Creative Commons licence, and indicate if changes were made. The images or other third party material in this article are included in the article's Creative Commons licence, unless indicated otherwise in a credit line to the material. If material is not included in the article's Creative Commons licence and your intended use is not permitted by statutory regulation or exceeds the permitted use, you will need to obtain permission directly from the copyright holder. To view a copy of this licence, visit http://creativecommons.org/licenses/by/4.0/.

\section{References}

1. DNV (2005) Fatigue assessment of ship structure, classification notes No. 30.7th edn, Høvik, Norway

2. ISSC (2018) In: Kaminski MK, Rigo P (eds) Proceedings of the 20th international ship and offshore structures congress, committee III. 2: Fatigue and fracture. The IOS Press
3. Fricke W, Cui W, Kierkegaard H, Kihl D, Koval M, Mikkola T, Parmentier G, Toyosada M, Yoon J-H (2002) Comparative fatigue strength assessment of a structural detail in a containership using various approaches of classification societies. Mar Struct 15(1):113. https://doi.org/10.1016/S0951-8339(01)00016-8

4. Li Z, Mao W, Ringsberg JW, Johnson E, Storhaug G (2014) A comparative study of fatigue assessments of container ship structures using various direct calculation approaches. Ocean Eng 82:65-74. https://doi.org/10.1016/j.oceaneng.2014.02.022

5. Olsen AS, Schrøter C, Jensen JJ (2006) Wave height distribution observed by ships in the North Atlantic. Ships Offshore Struct 1(1):1-12. https://doi.org/10.1533/saos.2005.0009

6. Mao W, Ringsberg JW, Rychlik I, Storhaug G (2010) Development of a fatigue model useful in ship routing design. J Ship Res 54(4):281-293

7. Mao W (2014) Development of a spectral method and a statistical wave model for crack propagation prediction in ship structures. J Ship Res 58(2):106-116. https://doi.org/10.5957/ JOSR.58.2.130050

8. Wang H, Mao W, Zhang D (2018) Voyage optimization for mitigating ship structural failure due to crack propagation. Proc Inst Mechanical Eng Part O J Risk Reliab 233(1):5-17. https://doi. org/10.1177/1748006X18754976

9. Jordan CR, Cochran CS (1978) In-service performance of structural details. Ship Structure Committee, Report SSC-272, US. Coast Guard, Washington, DC

10. Jordan CR, Knight LT (1980) Further survey of in-service performance of structural details, Ship Structure Committee, Report SSC-294, US. Coast Guard, Washington, DC

11. Bengtsson A, Rychlik I (2009) Uncertainty in fatigue life prediction of structures subject to gaussian loads. Probab Eng Mech 24(2):224-235. https://doi.org/10.1016/j.probengmec h.2008.06.004

12. Gaidai O, Storhaug G, Naess A, Ye R, Cheng Y, Xu X (2019) Efficient fatigue assessment of ship structural details. Ships Offshore Struct 15(5):503-510. https://doi.org/10.1080/17445 302.2019.1661623

13. Kim J-H, Kim Y (2019) Numerical simulation on the iceinduced fatigue damage of ship structural members in broken ice fields. Mar Struct 66:83-105. https://doi.org/10.1016/j.marst ruc.2019.03.002

14. Yamamoto N (2017) Fatigue evaluation of ship structures considering change in mean stress condition. Weld World 61(5):987-995. https://doi.org/10.1007/s40194-017-0461-x

15. Fricke W (2017) Fatigue and fracture of ship structures. In: Encyclopedia of maritime and offshore engineering. John Wiley \& Sons, Ltd, Chichester, pp. 1-12. https://doi. org/10.1002/9781118476406.emoe007

16. Thompson I (2018) Fatigue damage variation within a class of naval ships. Ocean Eng 165:123-130. https://doi.org/10.1016/j. oceaneng.2018.07.036

17. Mao W (2010) Fatigue assessment and extreme prediction of ship structures. Chalmers University of Technology, Gothenburg. Department of Mathematical Sciences Ph.D. Thesis

18. Mao W, Prasetyo FA, Ringsberg JW, Osawa N (2013) A comparison of two wave models and their influence on fatigue damage in ship structures. In: Volume 2A: structures, safety and reliability. American Society of Mechanical Engineers. https:// doi.org/10.1115/OMAE2013-10114

19. Bitner-Gregersen EM, Vanem E, Gramstad O, Hørte T, Aarnes OJ, Reistad M, Breivik Ø, Magnusson AK, Natvig B (2018) Climate change and safe design of ship structures. Ocean Eng 149:226-237. https://doi.org/10.1016/j.oceaneng.2017.12.023

20. De Gracia L, Wang H, Mao W, Osawa N, Rychlik I, Storhaug G (2019) Comparison of two statistical wave models for fatigue 
and fracture analysis of ship structures. Ocean Eng 187:106161. https://doi.org/10.1016/j.oceaneng.2019.106161

21. DNV GL (2015) Energy management study, Høvik, Norway

22. Reguero BG, Losada IJ, Méndez FJ (2019) A recent increase in global wave power as a consequence of oceanic warming. Nat Commun 10(205):1-14. https://doi.org/10.1038/s41467-01808066-0

23. DNV GL (2010) Recommended oractice, environmental conditions and environmental loads, DNV-RP-C205, Høvik, Norway

24. Mao W, Li Z, Ringsberg JW, Rychlik I (2012) Application of a ship-routing fatigue model to case studies of $2800 \mathrm{TEU}$ and 4400 TEU container vessels. Proc Inst Mech Eng Part M J Eng Marit Environ 226(3):222-234. https://doi.org/10.1177/14750 90212436606

25. EONav (2017) Earth observation for maritime navigation, H2020-EU.2.1.6

26. Marorka M (2010) excellence in maritime efficiency with data driven analytics. https://www.marorka.com/. Accessed $20 \mathrm{Jan}$ 2020

27. Mao W, Ringsberg JW, Rychlik I (2014) Crack growth analysis in ship structures using spectral methods, In: Proceedings of the 7th international conference on thin-walled structures

28. Rychlik I, Mao W (2019) Spatio-temporal modelling of wind speed variations and extremes in the Caribbean and the Gulf of Mexico. Theor Appl Climatol 135(3-4):921-944. https://doi. org/10.1007/s00704-018-2411-y

29. Hilderman A (2019) On flexible random field models for spatial statistics: Spatial mixture models and deformed spde models. Chalmers University of Technology, Gothenburg, Sweden, Department of Mathematical Sciences Ph.D. Thesis

30. Rychlik I (1987) A new definition of the rainflow cycle counting method. Int J Fatigue 9(2):119-121. https://doi.org/10.1016/01421123(87)90054-5

31. Ballou P, Chen H, Horner JD (2008) Advanced methods of optimizing ship operations to reduce emissions detrimental to climate change, In: OCEANS , IEEE, 2008, pp 1-12. https://doi. org/10.1109/OCEANS.2008.5151815

32. DNV GL (2018) Class guideline, wave loads, DNV GL-CG-0130, Høvik, Norway

33. Copernicus, Copernicus Climate Change Service Climate Data Store (CDS), 2019, Copernicus Climate Change Service (C3S): ERA5: Fifth generation of ECMWF atmospheric reanalyses of the global climate. Accessed 30 Jan 2019

34. Wang H, Lang X, Mao W, Zhang D, Storhaug G (2020) Effectiveness of $2 \mathrm{D}$ optimization algorithms considering voluntary speed reduction under uncertain metocean conditions. Ocean Eng 200:107063. https://doi.org/10.1016/j.oceaneng.2020.107063

35. Wang H, Mao W, Eriksson L (2019) A three-dimensional Dijkstra's algorithm for multi-objective ship voyage optimization.
Ocean Eng 186:106131. https://doi.org/10.1016/j.ocean eng.2019.106131

36. Wang H, Mao W, Eriksson L (2018) MetOcean data drived voyage optimization using genetic algorithm. In: Proceedings of the 28th international offshore and polar engineering conference

37. Wang H (2018) Voyage optimization algorithms for ship safety and energy-efficiency, Licentiate Thesis, Department of Mechanics and Maritime Sciences, Marine Technology, Chalmers University of Technology, Gothenburg, Sweden

38. James R (1975) Application of wave forecasts to marine navigation, Special publication. U.S, Naval Oceanographic Office

39. Hagiwara H (1989) Weather routing of (sail-assisted) motor vessels. Delft University of Technology, Delft, The Netherland Ph.D. Thesis

40. Bellman R (1952) On the theory of dynamic programming. Proc Natl Acad Sci 38(8):716-719. https://doi.org/10.1073/ pnas.38.8.716

41. Chen H (1978) A dynamic program for minimum cost ship routing under uncertainties. Department of Ocean Engineering, Massachusetts Institute of Technology, Cambridge, Massachusetts, USA Ph.D. Thesis

42. Shao W, Zhou P, Thong SK (2012) Development of a novel forward dynamic programming method for weather routing. J Mar Sci Technol 17(2):239-251. https://doi.org/10.1007/s0077 3-011-0152-Z

43. Zaccone R, Ottaviani E, Figari M, Altosole M (2018) Ship voyage optimization for safe and energy-efficient navigation: a dynamic programming approach. Ocean Eng 153:215-224. https://doi. org/10.1016/j.oceaneng.2018.01.100

44. Dijkstra EW (1959) A note on two problems in connexion with graphs. Numer Math 1(1):269-271. https://doi.org/10.1007/ BF01386390

45. Böttner C (2007) Weather routing for ships in degraded conditions. In: International symposium on safety security and environmental protection (April), pp 1-7

46. Skoglund L, Kuttenkeuler J, Rosen A (2012) A new method for robust route optimization in ensemble weather forecasts. KTH Aeronaut Veh Eng Trita-AVE 2012:67

47. ISO (2015) Ships and marine technology - guidelines for the assessment of speed and power performance by analysis of speed trial data ISO 15016

48. ITTC (2014) 1978 ITTC performance prediction method, ITTC recommended procedures and guidelines 7.5-02-03-01.4

Publisher's Note Springer Nature remains neutral with regard to jurisdictional claims in published maps and institutional affiliations. 